
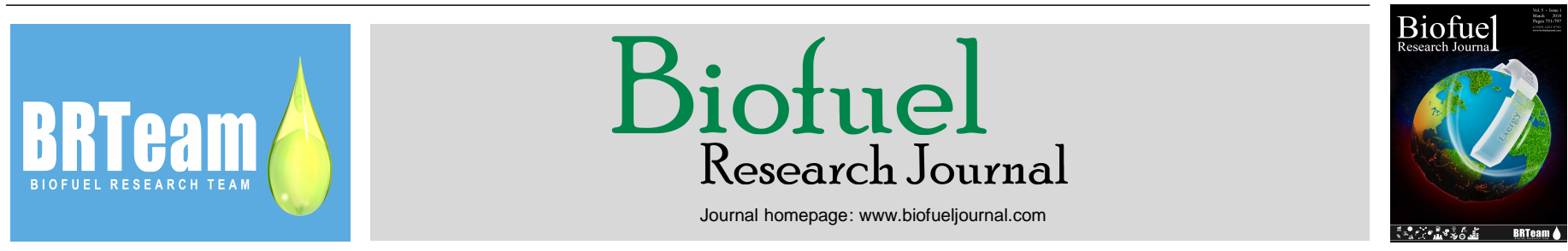

Review Paper

\title{
Current state and future prospects for liquid biofuels in Canada
}

\author{
Jennifer Littlejohns ${ }^{1, *}$, Lars Rehmann ${ }^{2}$, Rachel Murdy ${ }^{3}$, Aung $\mathrm{Oo}^{4}$, Stuart Neill $^{1}$
}

${ }^{I}$ National Research Council Canada, Low Carbon Fuels and Combustion, 1200 Montreal Road Building M-9, Ottawa, Ontario, Canada, K1A OR6.

${ }^{2}$ University of Western Ontario, Department of Chemical and Biochemical Engineering, Thompson Engineering Building, Room TEB 459, London, Ontario,

Canada, N6A 5B9.

${ }^{3}$ Lallemand Biofuels \& Distilled Spirits, 1815 Satellite Boulevard, Building 200, Duluth, GA 30097, USA.

${ }^{4}$ Western Sarnia-Lambton Research Park, Sarnia, Ontario, Canada.

\section{HIGHLIGHTS}

$>$ In Canada, the potential use of biomass for biofuels far exceeds current use.

$>$ Various technologies that range in TRL are being explored for biofuel production.

$>$ Advanced drop-in fuel development is beneficial for significant fuel switching.

$>$ A multifaceted approach to boost the liquid biofuels industry further is required.

\section{GRAPHICAL ABSTRACT}

\begin{tabular}{|c|c|c|c|c|c|}
\hline \multirow[t]{2}{*}{ Conversion } & \multirow[t]{2}{*}{ Product } & \multirow[t]{2}{*}{ Feedstock } & \multicolumn{3}{|c|}{ Level of activity in Canada } \\
\hline & & & R\&D & Demonstration & Commercialization \\
\hline \multirow{5}{*}{ Biochemical } & \multirow{3}{*}{ Ethanol } & Grain & & & Grain fermentation \\
\hline & & \multirow{2}{*}{ Lignocellulose } & \multicolumn{2}{|c|}{ Cellulose hydrolysis + fermentation } & \\
\hline & & & Cellulose fermentation & & \\
\hline & Butanol & \multirow{2}{*}{ Various } & Bioconversion & & \\
\hline & Other alcohols & & \multicolumn{2}{|c|}{ Various processes } & \\
\hline \multirow{11}{*}{$\begin{array}{l}\text { Thermochemical/ } \\
\text { chemical }\end{array}$} & \multirow{3}{*}{ Bio oil } & Lignocellulose & \multicolumn{3}{|c|}{ Fast pyrolysis } \\
\hline & & Lignocellulose & Hydrothermal liquifaction & & \\
\hline & & Lignocellulose & $\begin{array}{l}\text { Other thermal/catalytic } \\
\text { depolymerization }\end{array}$ & & \\
\hline & \multirow{3}{*}{ HDRD } & Fats and oils & Hydrotreating & & \\
\hline & & Lignocellulose & Bio oil production + hydrotreating & & \\
\hline & & Algae & Extraction and hydrotreating & & \\
\hline & \multirow{3}{*}{ Biodiesel } & Vegetable oils & & & Transesterification \\
\hline & & Waste fats and oils & \multicolumn{3}{|c|}{ Pretreatment and transesterification } \\
\hline & & Algae & Extraction and transesterification & & \\
\hline & Ethanol & Lignocellulose & \multicolumn{3}{|c|}{ Gasification + catalysis } \\
\hline & $\begin{array}{l}\text { Various drop-in } \\
\text { fuels }\end{array}$ & Lignocellulose & Gasification + Fischer-Tropsch & & \\
\hline & \multicolumn{5}{|c|}{ Applications } \\
\hline & Transportation w & thengine modificatio & 'blending & & \\
\hline & \multicolumn{5}{|c|}{ Stationary } \\
\hline & \multicolumn{5}{|c|}{$\begin{array}{l}\text { Both Stationary and transportation with engine modifications/blending } \\
\text { Drop-in }\end{array}$} \\
\hline
\end{tabular}

\section{ARTICLE INFO}

\section{Article history:}

Received 2 December 2017

Received in revised form 3 January 2018

Accepted 3 January 2018

Available online 1 March 2018

\section{Keywords:}

Biofuel feedstock

Biochemical conversion

Thermochemical conversion

Biofuel applications

Liquid biofuel

Canada

\begin{abstract}
The necessity to find renewable and low carbon fuels as a critical component of the strategy to reduce greenhouse gas emissions in Canada has caused the biofuels industry to rapidly expand. However, there is a higher capacity for the use of biofuels to replace conventional petroleum fuels in Canada than outlined by current regulations and programs. A wide range of feedstocks, processes, and applications for liquid biofuels can be found in Canada at varying degrees of progress. To reach the full potential of the biofuels industry in Canada, it is important to understand the broad landscape of the biofuels industry and areas of promise. The objective of this paper is to provide a comprehensive overview of the current state of liquid biofuels in Canada. This includes national feedstock availability and conversion processes to produce liquid biofuels. Both biochemical and thermochemical processes over a wide range of technology readiness levels, from R\&D to commercialization, will be included. Current industry, government, and/or academic support for these production activities will be referenced where applicable. The transportation applications of commercially available liquid biofuels in Canada will be reviewed. Finally, comments on future prospects to boost environmental and economic competitiveness of the biofuels industry in Canad a will be provided.
\end{abstract}

(C) 2018 BRTeam. All rights reserved.

* Corresponding author at: Tel.: (+1) 613-993-0810 E-mail address: Jennifer.littlejohns@nrc-cnrc.gc.ca

Please cite this article as: Littlejohns J., Rehmann L., Murdy R., Oo A., Neill S. Current state and future prospects for liquid biofuels in Canada. Biofuel Research Journal 17 (2018) 759-779. DOI: 10.18331/BRJ2018.5.1.4 


\section{Contents}

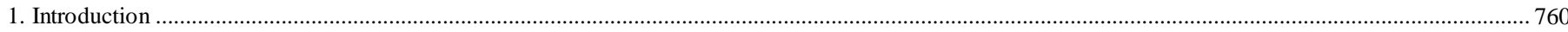

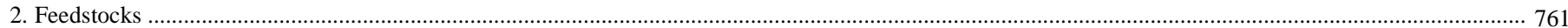

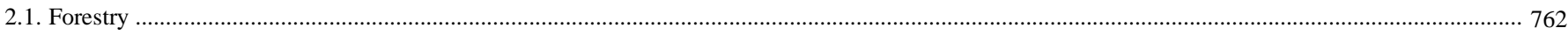

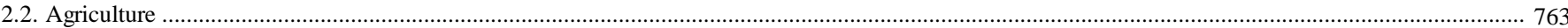

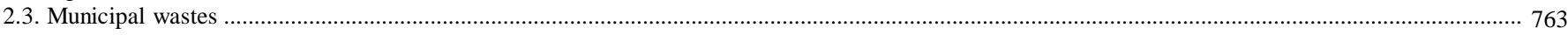

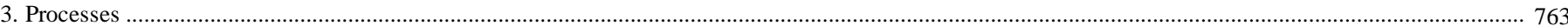

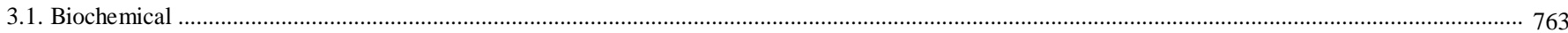

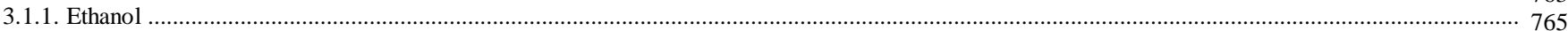

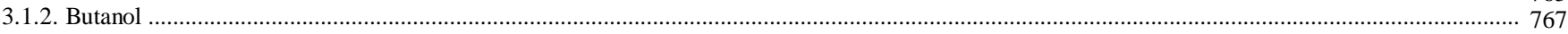

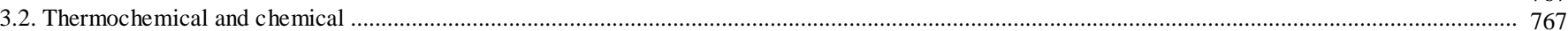

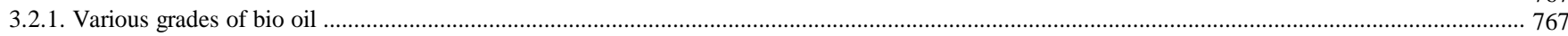

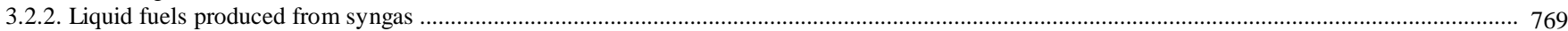

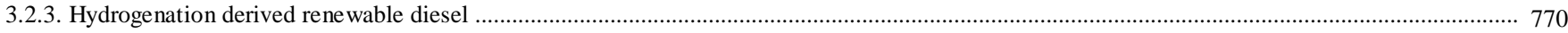

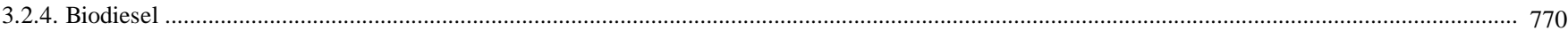

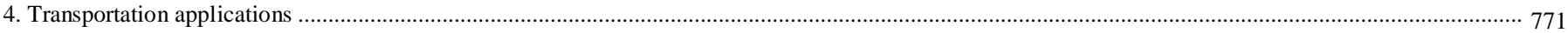

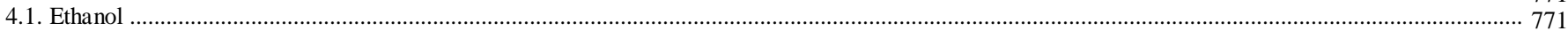

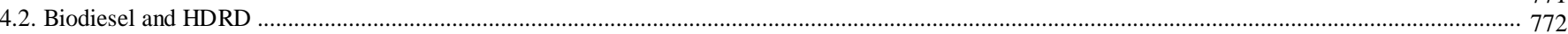

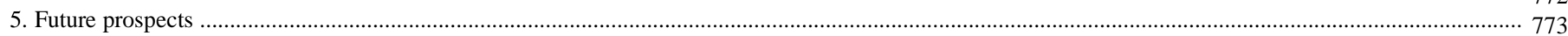

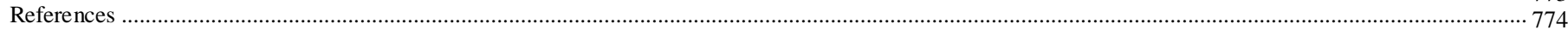

\section{Introduction}

In response to rising greenhouse gas (GHG) emissions from petroleum fuels, sources of renewable fuels that reduce the net carbon output to the atmosphere are being intensely researched and commercialized in Canada. The conversion of biomass to fuel is an attractive renewable option and bioenergy currently accounts for approximately 6\% of Canada's total energy supply (NRCan, 2017). Various biomass feedstocks are widely availabile in Canada and there is a larger capacity for biofuel production than what is currently being utilized (Surisetty et al., 2012). Liquid biofuels that are produced commercially in Canada are primarily ethanol and biodiesel. Nevertheless, there is a wide range of technology readiness levels (TRL) of emerging biofuel products and production processes that have the potential for improved efficiency and reduced carbon footprint. The lower TRL biofuels have the potential to contribute significantly to Canada's biofuel supply. For example, it was estimated that bioethanol production from all available sources of lignocellulosics could provide up to 50\% of Canada's 2006 transportation fuel requirements, assuming ideal conversion and unlimited access to feedstocks (Mabee and Saddler, 2010). Liquid biofuels can be used in internal combustion engines with or without blending and with or without some engine modifications, depending on type (Agarwal, 2007), but the feasibility of replacing 50\% of transportation fuel with bioethanol is unlikely considering the infrastructure changes required. This scenario would likely make Canada a major exporter of bioethanol. Perhaps the most noteworthy benefit to transitioning to liquid biofuels is the potential to significantly reduce GHG emissions relative to petroleum depending on biofuel type and conversion process (Larson, 2006), which was the policy intent of supporting the biofuels industry. However, it should be noted that the life cycle analysis of biofuel production is challenging, including such complexities as GHG emissions from feedstock production and land use changes (Dyer et al., 2010).

Over two decades ago, Canada formally identified the bioenergy sector as an opportunity for sustainable economic development, with additional benefits to employment, environment, health, waste management, and secured energy supply (Le Roy and Klein, 2012). Regulations on renewable fuel content has been implemented in Canada over the past decade with the specific objective of reducing GHG emissions and boosting the biofuel industry. For both gasoline and distillate pools, there are federal and often provincial regulations for renewable fuel content. This renewable fuel standard (RFS) is summarized in Table 1 for locations across Canada. In addition, a low carbon fuel standard (LCFS) has been implemented in British Columbia and is being proposed in Ontario as well by the federal government, which is also shown in Table 1 . At the time of writing the current review, Environment and Climate Change Canada was developing new regulation under the Canadian Environmental Protection Act of 1999 to reduce Canada's GHG emissions by 30 mega tonnes annually by 2030 through increased use of low carbon fuels and alternative technologies (ECCC, 2017). This new regulation would be applicable for not only transportation fuels, but gas, liquid, and solid fuels for both motive and stationary applications and will be a key driver that shapes the Canadian biofuels industry in the future. The role of policy on the reduction of GHGs and adoption of biofuel use has been shown to be effective, as, by 2015 , regulations led to to reduce GHG emissions by $4.4 \mathrm{Mt}$ and increased biofuel use to 2800 million L ethanol, 470 million L biodiesel, and 150 million L renewable diesel/year (Wolinetz and Hein, 2017).

Besides regulations, several programs have also been put in place by the federal government to provide financial support to the development of the biofuels industry in Canada. These programs have targeted the three major industries involved in biofuel production: 1 . feedstock production and availability, 2. conversion technologies to convert feedstocks to biofuel, and 3. end-use. These programs are/were led by such organizations as Natural Resources Canada (e.g., ecoENERGY for biofuels, The National Renewable Diesel Demonstration Initiative), Sustainable Development Technology Canada (e.g., NextGen Biofuels Fund, Sustainable Development Technology Fund), and Agiculture and AgriFoods Canada (e.g., AAFC Growing Forward). In addition, Networks of Centres of Excellence of Canada provided support for the national organization, Biofuelnet, to integrate work being completed in academia with industry, investors, and government to collaborate on projects to develop non-food feedstocks for biofuel production. There are also extensive programs that were put in place in the past to provide a boost to the Canadian ethanol industry that support production, capital investment, distribution, and consumption including the Ethanol Expansion Program, as reviewed by Laan et al. (2009). Several of the aforementioned government supported programs have now ended or are ending shortly, with other options for funding for various stages of development being strengthened or put in place. Examples include Innovation, Science, and Economic Development Canada's Innovation Superclusters Initiative to provide funding to industry-led consortiums, to which biofuels may play a role, the Strategic Innovation Fund and the Low Carbon Economy Fund. In addition, the Clean Growth Hub initiative has been implemented to streamline the application of potential commercial ventures for funding. There is also support for R\&D from the federal government, which include programs through the National Research Council and the Agricultural Bio-products Innovation Program, as well as the networks Cellulosic Biofuel Network (CBN), and the Strategic Network in the Bioconversion of Lignocellulosic, which are funded through Agriculture and Agrifood Canada and Natural Sciences and Engineering Research Council of Canada (NSERC), respectively. A concise summary of federal and provincial programs in Canada to support biofuels production and R\&D can be found in Scaife et al. (2015). There are various other organizations in Canada that promote and advocate for biofuel producers including the non-profit Renewable Industries Canada and the industry association Advanced Biofuels Canada. There is evidence of strong support for the biofuels industry throughout the public and private sector.

It is important to understand how biofuel production and use in Canada is currently positioned to meet the intended outcome of regulations, which is to ultimately transition to a renewable fuel industry. This review will 
Table 1.

Summary of federal and provincial regulations for renewable fuel content in Canada in 2017, including renewable fuel standard (RFS) and low carbon fuel standard (LCFS)*

\begin{tabular}{|c|c|c|c|c|c|c|}
\hline \multirow{3}{*}{ Location } & \multicolumn{4}{|c|}{ Renewable fuel standards } & \multicolumn{2}{|c|}{ Low carbon fuel standards } \\
\hline & \multicolumn{2}{|c|}{ Provincial } & \multicolumn{2}{|l|}{ Federal } & \multirow[t]{2}{*}{ Provincial } & \multirow[t]{2}{*}{ Federa } \\
\hline & Gasoline & Diesel & Gasoline & Diesel & & \\
\hline Ontario & $5 \%^{\mathrm{a}}$ & $\begin{array}{l}4 \%-70 \% \text { reduction in } \\
\text { lifecycle } \mathrm{GHG}^{\mathrm{b}}\end{array}$ & $5 \%{ }^{\mathrm{c}}$ & $2 \%^{\mathrm{c}}$ & TBD & TBD \\
\hline British Columbia & $5 \% \mathrm{~d}$ & $4 \%^{\mathrm{d}}$ & $5 \% \mathrm{c}$ & $2 \% c$ & $\begin{array}{l}10 \% \text { reduction in GHG by } \\
2020^{\mathrm{d}}\end{array}$ & TBD \\
\hline Newfoundland & - & - & Excluded $^{\mathrm{c}}$ & Excluded $^{\mathrm{c}}$ & - & $\mathrm{TBD}$ \\
\hline Nova Scotia & - & - & $5 \%{ }^{\mathrm{c}}$ & $2 \% \mathrm{c}$ & - & TBD \\
\hline Prince Edward Island & - & - & $5 \%$ c & $2 \%^{\mathrm{c}}$ & - & TBD \\
\hline New Brunswick & - & - & $5 \%$ c & $2 \%^{\mathrm{c}}$ & - & TBD \\
\hline Quebec & - & - & $5 \% /$ north of 60 excluded $^{\mathrm{c}}$ & $2 \% /$ north of 60 excluded $^{\mathrm{C}}$ & - & TBD \\
\hline Manitoba & $8.5 \%$ & $2 \%^{\mathrm{f}}$ & $5 \%$ & $2 \%^{\mathrm{c}}$ & - & $\mathrm{TBD}$ \\
\hline Saskatchewan & $7.5 \%^{\mathrm{g}}$ & $2 \%^{\mathrm{h}}$ & $5 \%$ c & $2 \%^{\mathrm{c}}$ & - & TBD \\
\hline Alberta & $5 \%^{\mathrm{i}}$ & $2 \%^{\mathrm{i}}$ & $5 \% \mathrm{c}$ & $2 \%^{c}$ & - & TBD \\
\hline Yukon & - & - & Excluded $^{\mathrm{c}}$ & Excluded $^{\mathrm{c}}$ & - & TBD \\
\hline Northwest Territories & - & - & Excluded $^{\mathrm{c}}$ & Excluded $^{\mathrm{c}}$ & - & TBD \\
\hline Nunavut & - & - & Excluded $^{\mathrm{c}}$ & Excluded $^{\mathrm{c}}$ & - & TBD \\
\hline
\end{tabular}

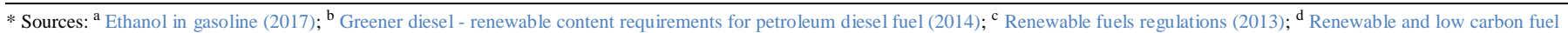

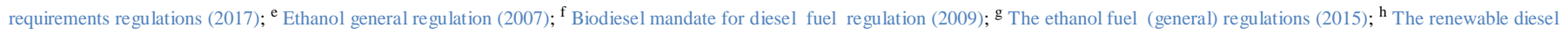
regulations (2012); and ${ }^{\mathrm{i}}$ Renewable Fuel Standard Regulation (2012).

focus on the current state of biofuels in Canada, including feedstock use and availability, processes to convert biomass to fuels at various scales and TRLs, and applications for commercially available biofuels. Feedstocks that will be reviewed include biomass from agriculture and forestry, as well as others commonly used in Canada. An overview of prominent and emerging liquid biofuel production processes will be provided; however, details of mechanisms and conversion chemistry behind the technologies will not be included, as that information can be found reviewed elsewhere (e.g., Naik et al., 2010; Nigam and Singh, 2011). Transportation applications for commercially produced liquid biofuels will also be discussed in the current document including compatibility and barriers to implementation. Finally, comments on future prospects in the biofuels industry in Canada will be provided.

\section{Feedstocks}

Canada is endowed with abundant natural resources such as oil, gas, uranium, hydro, minerals, and biomass. As the second largest country in the world, Canada has enormous biomass resources from its large forest area and well-developed agricultural lands. Municipal wastes also present biomass resources with considerable opportunities to reduce GHG emissions from the current landfill sites. Various biomass feedstocks can be used to produce a wide range of commodities, including fuels, chemicals, foods, energy, and other consumer products. Given the scale of its biomass resources, Canadian forestry and agricultural sectors can sustainably provide foods, fuels, and other commodities. Experts agree that Canada, the USA, and Brazil are the most promising countries to develop a large-scale bioeconomy sector due to their sustainable biomass resources.

A few studies have performed comprehensive assessments of biomass resources from Canadian forests, agricultural land, and municipal wastes (Wood and Layzell, 2003; Bradley, 2008; Paré et al., 2017). Based on the findings of these studies, the total energy content of all available biomass resources, which could be sustainably produced, is estimated to be approximately $5.3 \mathrm{EJ} / \mathrm{yr}$. The relative quantities of annual biomass production from the forestry, agricultural, and municipal solid waste sectors are shown in Figure 1. Canada, which possesses approximately $10 \%$ of world forests, obviously offers the forestry materials as its largest source of biomass feedstock (58\% of total). The agricultural biomass and municipal wastes represent $39 \%$ and $3 \%$, respectively, of total biomass available annually.

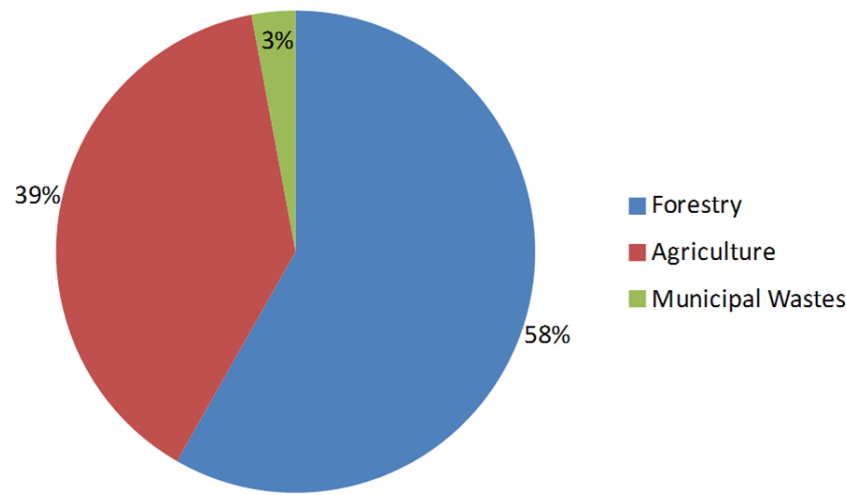

Fig. 1. Relative quantities of annual biomass production in Canada (Total 5.3 EJ/yr; Source: Bradley (2008); Paré et al. (2017); and Wood and Layzell (2003)).

It should be noted that the majority of the biomass produced are for food and other commodities such as lumber for construction applications. Residues from harvesting operations in the forestry and agricultural sectors and biomass materials from municipal wastes are mostly unused at present. Figure 2 exhibits biofuel potential in Canada under different scenarios compared to current biofuel production of ethanol and biodiesel. It is assumed that $70 \%$ of energy in biomass feedstock is converted to ethanol and biodiesel in biofuel production processes. The weighted average energy density, based on the current production of ethanol and biodiesel, of 21.12 $\mathrm{MJ} / \mathrm{L}$ is used to calculate the biofuel potential. The current productions of 1,850 and 150 million $\mathrm{L}$ are estimated for ethanol and biodiesel, respectively (Bradley, 2008; Bradburn, 2014).

As seen in Figure 2, if all biomass resources annually available are used as biofuel feedstock, approximately 176,000 million L of biofuel could be sustainably produced in Canada. This scenario is obviously hypothetical since the majority of biomass resources will be continued to serve as food supply and feedstock for other commodities. However, $10 \%$ of biomass resources available can be converted to approximately 18,000 million $\mathrm{L}$ of 


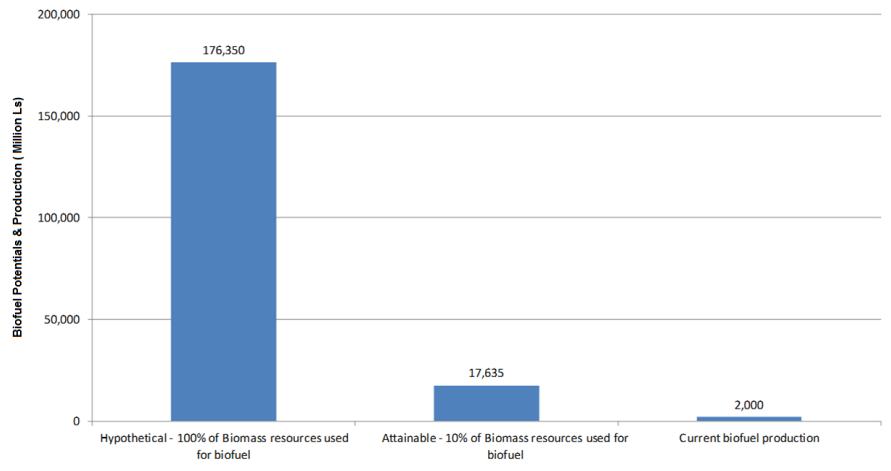

Fig. 2. Biofuel potentials/production in Canada.

biofuel. Harvest residues in the forestry and agricultural sectors and biomass from municipal wastes represent well more than $10 \%$ of total available biomass resources (Wood and Layzell, 2003; Bradley, 2008; Paré et al., 2017). The economical production at current supply and demand is approximately 2,000 million $\mathrm{L}$ which is well below the attainable potential. It can be stated that Canada's biofuel sector is not feedstock-limited. The biomass resources could contribute at a significantly higher level to reducing the GHG emissions in transportation and stationary applications.

\subsection{Forestry}

Forests are a major source of biomass in Canada. Though Canada has only $0.4 \%$ of the world's population, it possesses approximately $10 \%$ of world forests (Global Forest Watch - Country Profiles, 2017). Canada is the second largest country in the world, with almost 1,000 million hectares, and with $45 \%$ of the land covered by forests. There are three main types of biomass feedstock potentially available from the forestry sector: roundwood, residues from harvest and forest management operations, and residues from sawmills and industrial processes.

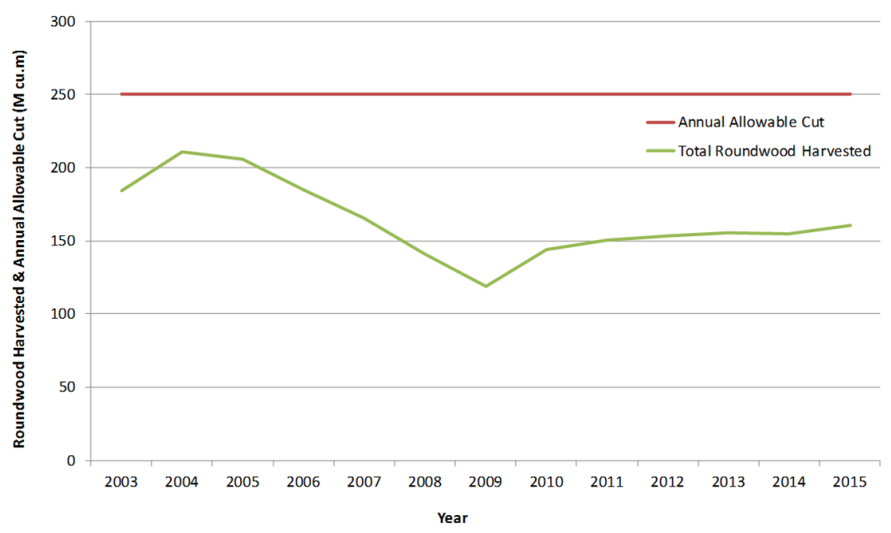

Fig. 3. Total roundwood harvested compared to Annual Allowable Cut (Source: National Forestry Database - Forest Inventory ( 2017) and Statistics Canada).

Total roundwood, which is usually harvested and processed into conventional forestry products, harvested in Canada is given in Figure 3 compared with Annual Allowable Cut (AAC) (National Forestry Database Forest Inventory, 2017). Canadian forests grow the AAC of approximately 250 million $\mathrm{m}^{3}$ of roundwood although the estimate varies slightly year to year. The total roundwood harvested has been well below the AAC as shown in Figure 3. In 2015, the difference between the AAC and the total roundwood harvested was 90 million $\mathrm{m}^{3}$, which could be used to produce approximately 52,000 million L of biofuel.

Utilizing roundwood as feedstock for biofuel has both advantages and disadvantages. Roundwood is a consistent and quality feedstock compared to residues. Additional harvest equipment and infrastructure are not required as the Canadian forestry industry is not at full capacity as seen in Figure 3. If the demand and economics of producing biofuel from roundwood is warranted, the industry could deliver feedstock since the supply chain is well-developed. One of the disadvantages of roundwood as a feedstock is likely the cost compared to residues as competition from conventional forestry products is expected.

Roundwood harvested for conventional forestry products leaves behind residues, tree tops and branches in forests and roadsides. Residues are also generated from forestry management operations, such as thinning and natural disturbances. The accurate estimation of these residues is some what difficult, and previous studies have suggested a range of $20-40 \%$ of total roundwood harvested as compiled by Paré et al. (2017). Leaving some residues at the harvest sites offers ecological benefits. If the conservative residues-to-roundwood of $20 \%$ and the removal rate of $50 \%$ are assumed, the potential harvest residues present approximately 18 million $\mathrm{m}^{3}$ or 10,000 million $\mathrm{L}$ of biofuel. The majority of residues are left at the harvest sites at present due to limited uses and the poor economics of collection.

Sawmills and industrial processes generate residues in the form of sawdust, bark, shavings, and black liquor. The estimation of these residues is more accurate since the material flows of the industrial processes are relatively invariable. Most of these mill residues are currently used to produce value-added forestry products and to co-generate heat and electricity. Mill residues are the major feedstock, representing approximately $80 \%$ of wood pellets produced in Canada (Bradburn, 2014). Wood and Layzell (2003) estimated that about 22\% of roundwood processed ended up as residues and approximately $70 \%$ of mill residues were converted to energy or value-added products. Based on their estimates, available mill residues (about $30 \%$ of total mill residues) for biofuel production is approximately 11 million $\mathrm{m}^{3}$ or 6,000 million $\mathrm{L}$ of biofuel, which is about three times higher than the current biofuel production in Canada.

Although harvest and mill residues as feedstock for biofuels offer an efficient utilization of biomass resources, a number of factors should be considered for their viability. The impurity and inconsistent quality of residues may lead to higher processing costs in biofuel production. Collection of harvest residues will likely require additional equipment, hence investments. Although the costs of harvest residues are perceived to be lower than that of roundwood, the difference may not be substantial due to the volume of residues available per $\mathrm{km}^{2}$. Barks, which are rich in mineral content and require additional processing prior to biofuel production, represents a significant portion of unused mill residues.

The costs of forestry biomass will vary from province to province in Canada and will also depend on the types of biomass. However, the spot price for wood pellets delivered into the Amsterdam-Rotterdam-Antwerp (ARA) in Europe provides a basis to estimate the cost of forestry biomass. Canada produced about 2.3 million tonnes of wood pellets in 2013 and $86 \%$ of total pellets were exported, mainly to Europe (Bradburn, 2014). The feedstocks for wood pellets include roundwood, harvest residues, and mill residues. Several Canadian provinces, from New Brunswick and Nova Scotia to Alberta and British Columbia, are producing wood pellets for export markets.

The spot price of wood pellets at ARA has recovered from its lows in early 2017, and is currently at US\$140-150/tonne or approximately C $\$ 180 /$ tonne. Based on communications with industry experts, the average transportation cost of $\mathrm{C} \$ 40 /$ tonne from Canada to Europe and the pelletization cost of $\mathrm{C} \$ 40 /$ tonne are estimated. Assuming $15 \%$ margin for pellet manufacturers, the estimated cost of forestry biomass in Canada is in the range of $\mathrm{C} \$ 50-75 /$ tonne delivered at biofuel facilities.

The Canadian forestry sector is potentially the largest source of biomass feedstock, which can be converted to biofuel and bio-chemicals such as methanol through different bio-chemical and thermo-chemical processes. However, the economic feasibility of biofuel from forestry biomass, e.g., 
cellulosic ethanol production, has yet to be proven on commercial scales. The changing policy drivers and improvements in conversion technologies may lead to the utilization of these sustainable resources for biofuel production in both ecologically and economically beneficial manners in the future.

\subsection{Agriculture}

Canada has 67.5 million hectares of agricultural land, representing $6.8 \%$ of total land area. Field crops are grown on over half of the agricultural land producing approximately 120 million tonnes of biomass annually for food, feed, and feedstock for biofuel and other industrial applications. Three major types of biomass which could be used as feedstock for biofuel production are field/special crops, agricultural residues, and livestock wastes.

The major field and special crops of Canada are given in Table 2. Wheat is the largest crop followed by canola and tame hay in terms of seeded areas. The Canadian agricultural sector has been the main source of feedstock for commercial biofuel production. As shown in Table 2, approximately 25\% of grain corn produced is used as biofuel feedstock. Wheat is the second largest biofuel feedstock; about $3 \%$ of wheat produced is converted to biofuel. Other Canadian field crops for commercial biofuel production are canola and soybeans. The starchy crops, grain corn and wheat, are feedstock for ethanol while the oily crops, canola and soybeans, are used for biodiesel. Approximately 5 million tonnes out of 120 million tonnes total of field/special crops are currently used as biofuel feedstock annually in Canada. The agricultural sector can obviously offer more feedstock from its field/special crop production.

Table 2.

Major field/special crops and feedstock for biofuel production in Canada in 2016*.

\begin{tabular}{lllll}
\hline & \multirow{2}{*}{$\begin{array}{l}\text { Seeded area } \\
\text { ('000 Ha) }\end{array}$} & $\begin{array}{l}\text { Production } \\
\text { ('000 tonnes) }\end{array}$ & \multicolumn{2}{c}{ Used as biofuel feedstock } \\
\cline { 5 - 6 } Field Crops & & & & \\
\hline All wheat & $9,420.1$ & $31,728.6$ & 950 & 2.99 \\
Canola & $8,235.9$ & $19,600.5$ & 550 & 2.81 \\
Barley & $2,586.1$ & $8,783.6$ & - & - \\
Oats & $1,159.1$ & $3,194.6$ & - & - \\
Flexseed & 384.5 & 588.0 & - & - \\
Rye & 164.3 & 415.0 & - & - \\
Soybeans & $2,212.5$ & $6,462.7$ & 333 & 5.15 \\
Grain corn & $1,345.4$ & $13,193.1$ & 3250 & 24.63 \\
Tame hay & $6,676.9$ & $27,564.0$ & - & - \\
\hline Special Crops & & & & - \\
\hline Canary seed & 105.2 & 140.3 & - & - \\
Lentils & $2,371.5$ & $3,248.2$ & - & - \\
Sunflower seed & 28.3 & 50.6 & - & - \\
Mustard seed & 212.3 & 235.6 & - & - \\
Dry peas & $1,715.3$ & $4,835.9$ & - & \\
\hline * Source: Statistics Canada and Dessureault $(2016)$ & & & \\
\hline
\end{tabular}

The Canadian agricultural sector also produces significant tonnages of residues such as corn stover and straws as by-products every year. The majority of agricultural residues should be left in fields to maintain soil organic matter (SOM). However, some residues can be harvested or removed from the field for biofuel and other applications. Based on the SOM balance model, a total of 2.8 million tonnes of agricultural residues could have been sustainably harvested in 2009 in Ontario without degrading the soil (Oo et al., 2010). This quantity represents approximately $20 \%$ of the total above ground agricultural residues produced in Ontario. By applying the same harvestable residues to farm area ratio, a total of over 30 million tonnes of agricultural residues could be sustainably harvested from Canadian farms. The commercial production of biofuel from agricultural residues and other cellulosic materials, however, has yet to be seen, and most of the agricultural residues are left in the fields at present.
Livestock wastes represent an energy source although they are mainly used for soil amendment at present. Canada's livestock farms also produce 58 million tonnes of manure annually, which if made available for biogas production through the anaerobic digestion process, would generate approximately $65 \mathrm{PJ}$ of biogas, equivalent to the energy content in 3.5 million dry tonnes of biomass (Wood and Layzell, 2003). Biogas from livestock wastes could be converted to methanol to be used as fuel additives. Methane and nitrous oxides emitted from the current use of livestock wastes are strong GHGs and can be substantially reduced through the anaerobic digestion process.

Grain corn is the largest feedstock for biofuel production in North America, since it is likely the most cost competitive starchy crop in the region. The field crops used to manufacture biofuel are commoditized and their prices are available at publicly traded markets such as Chicago Board of Trade (Chicago Board of Trade, 2017).

However, the price of crop residues could be crop and site specific. The recent estimates by the Western Sarnia-Lambton Research Park and Ontario Federation of Agriculture suggest that the price of agricultural residues could range from $\mathrm{C} \$ 75$ to $\mathrm{C} \$ 100 /$ tonne delivered at biofuel facilities. Based on personal communication with industry experts, the bulk purchase of livestock wastes ranges from $\mathrm{C} \$ 3$ to $\mathrm{C} \$ 10 /$ tonne at farm gate; anaerobic digestors are likely farm-based operations since off-farm transportation of a large amount of livestock wastes is prohibited in many jurisdictions.

\subsection{Municipal wastes}

Canadians produced approximately $706 \mathrm{~kg}$ of waste/person according to 2014 Statistics Canada data. Of this, $451 \mathrm{~kg}$ went to landfills or was incinerated while only $255 \mathrm{~kg}$ was diverted from landfill. Some municipal wastes currently not diverted, approximately 16 million tonnes, could potentially be feedstock for biofuel production. Although total volume of municipal wastes is relatively small compared to potential feedstock from forestry and agricultural sectors, the diversion from landfill eliminates the severe environmental impacts of the landfill process. Assuming $50 \%$ of landfill waste has biomass potential and an average moisture content of $30 \%$, there is a potential of 5.6 million dry tonnes of biomass-equivalent available from municipal wastes in Canada.

There are three main types of municipal wastes: residential; industrial, commercial, and institutional (IC\&I); and construction and demolition (C\&D). Residential wastes, which account for about $40 \%$ of total, are the least diverted materials due to the poor economics and/or difficulty in the separation of recyclable materials from other wastes. Municipal wastes from IC\&I and C\&D are better managed for diversion. Municipal wastes offer biomass feedstock at negative costs, since the tipping fees at landfill sites average approximately US\$50/tonne (Green Power Inc., 2014). However, municipal wastes are the most challenging feedstock for energy conversion processes. The production of biofuel from municipal waste is mostly in research and development stages at present.

\section{Processes}

Processes for the production of liquid biofuels can be split into two major categories: biochemical conversion and thermochemical/chemical conversion. These two categories of processes will be described in the following sections.

\subsection{Biochemical}

Microbial fermentation remains the primary method for the production of liquid biofuels in Canada. Domestic fuel ethanol production is driven by both federal and provincial mandates. The federal mandate requires $5 \%$ of gasoline be blended with renewable fuel, and provinces have also implemented either equivalent or higher provincial mandates, as listed in Table 1. In order to meet the blend mandate, Canada was estimated to require over 2 billion L of ethanol in 2016 (Dessureault, 2016). Domestic ethanol production in 2016 totaled 1.75 billion $\mathrm{L}$ at 14 ethanol plants located in Quebec, Ontario, Manitoba, Saskatchewan, and Alberta, which can be seen listed in Table 3, with 1 billion L imported from the United States. 
Table 3.

A summary of commercial and demonstration biofuel production plants in Canada*.

\begin{tabular}{|c|c|c|c|c|c|c|}
\hline & Company/Location & Fuel Product & Process & Feedstock & Scale & $\begin{array}{l}\text { Capacity } \\
\text { (Million L/Year) }\end{array}$ \\
\hline \multirow{16}{*}{ 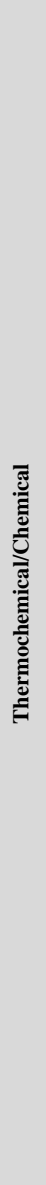 } & Ensyn, Renfrew, ON & Renewable fuel oil & Thermochemical - Fast Pyrolysis, RTP & Wood residues & Commercial & 11 \\
\hline & Enerkem, Westbury, QC & Methanol/Ethanol & $\begin{array}{l}\text { Thermochemical - Syngas to methanol } \\
\text { to ethanol via catalysis }\end{array}$ & Various wood based & Demonstration & 5 \\
\hline & Enerkem, Edmonton, $\mathrm{AB}$ & Methanol/Ethanol & $\begin{array}{l}\text { Thermochemical - Syngas to methanol } \\
\text { to ethanol via catalysis }\end{array}$ & $\begin{array}{l}\text { Municipal solid waste } \\
\text { (MSW) }\end{array}$ & Commercial & 38 \\
\hline & Woodland Biofuels, Sarnia, ON & Ethanol & $\begin{array}{l}\text { Thermochemical - Syngas to ethanol via } \\
\text { catalysis }\end{array}$ & $\begin{array}{l}\text { Various (wood, ag and } \\
\text { paper waste, MSW) }\end{array}$ & Demonstration & 2 \\
\hline & $\begin{array}{l}\text { Archer Daniels Midland (ADM), } \\
\text { Lloydminster, AB }\end{array}$ & Biodiesel & Chemical & Canola & Commercial & 265 \\
\hline & Atlantic Biodiesel, Welland, ON & Biodiesel & Chemical - Kosher status & Canola and soy & Commercial & 170 \\
\hline & BIOX Corporation, Hamilton, ON & Biodiesel & $\begin{array}{l}\text { Chemical - Two step, single-phase } \\
\text { continuous process }\end{array}$ & Multi-feedstock & Commercial & 66 \\
\hline & BIOX Corporation, Sombra, ON & Biodiesel & $\begin{array}{l}\text { Chemical - Two step, single-phase } \\
\text { continuous process }\end{array}$ & Multi-feedstock & Commercial & 50 \\
\hline & Consolidated Biofuels Ltd., Delta, BC & Biodiesel & Chemical-Two-step process & $\begin{array}{l}\text { Rendered beef tallow and } \\
\text { restaurant grease }\end{array}$ & Commercial & 11 \\
\hline & Cowichan Biodiesel Coop, Duncan, BC & Biodiesel & Chemical & Recycled vegetable oil & Commercial & 0.2 \\
\hline & Evoleum, St-Jean-d-lberville, QC & Biodiesel & Chemical & Recycled vegetable oil & Commercial & 10 \\
\hline & Innoltek, Thetford Mines, QC & Biodiesel & Chemical & Yellow grease & Commercial & 6 \\
\hline & $\begin{array}{l}\text { Methes Energies Canada Inc.,Mississauga, } \\
\text { ON }\end{array}$ & Biodiesel & $\begin{array}{l}\text { Chemical - Combined } \\
\text { esterification/transesterification step } \\
\text { with PP-MEC Catalyst }\end{array}$ & Yellow grease & $\begin{array}{l}\text { Demonstration } \\
\text { "compact processor" }\end{array}$ & 5 \\
\hline & Milligan Bio-Tech Inc, Foam Lake, ON & Biodiesel & Chemical & Canola oil & Commercial & 20 \\
\hline & $\begin{array}{l}\text { Noroxel Inc. (Methes Energies Canada Inc. } \\
\text { installation), Springfield, ON }\end{array}$ & Biodiesel & $\begin{array}{l}\text { Chemical - Combined } \\
\text { esterification/transesterification step } \\
\text { with PP-MEC Catalyst }\end{array}$ & Yellow grease & $\begin{array}{l}\text { Commercial } \\
\text { "Compact } \\
\text { processor" }\end{array}$ & 5 \\
\hline & $\begin{array}{l}\text { Rothsay Biodiesel, Ville Ste. Catherine, } \\
\text { QC }\end{array}$ & Biodiesel & Chemical - Three step process & $\begin{array}{l}\text { Animal fats, recycled } \\
\text { cooking oil }\end{array}$ & Commercial & 45 \\
\hline \multirow{14}{*}{ 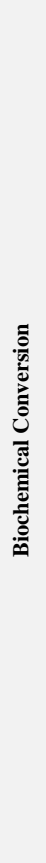 } & Greenfield Global, Chatham, ON & Ethanol & Fermentation, Sugar/Starch Platform & Corn & Commercial & 195 \\
\hline & Greenfield Global, Johnstown, ON & Ethanol & Fermentation, Sugar/Starch Platform & Corn & Commercial & 260 \\
\hline & Greenfield Global, Tiverton, ON & Ethanol & Fermentation, Sugar/Starch Platform & Corn & Commercial & 27 \\
\hline & Greenfield Global, Varennes, ON & Ethanol & Fermentation, Sugar/Starch Platform & Corn & Commercial & 175 \\
\hline & Husky Energy, Lloydminster, SK & Ethanol & Fermentation, Sugar/Starch Platform & Other Grains & Commercial & 130 \\
\hline & Husky Energy, Minnedosa, MB & Ethanol & Fermentation, Sugar/Starch Platform & Corn & Commercial & 130 \\
\hline & IGPC Ethanol Inc., Alymer, ON & Ethanol & Fermentation, Sugar/Starch Platform & Corn & Commercial & 170 \\
\hline & Iogen Corporation, Ottawa, ON & Ethanol & Fermentation, Cellu losic & Crop Residue & Demonstration & 2 \\
\hline & Kawartha Ethanol Inc., Havelock, ON & Ethanol & Fermentation, Sugar/Starch Platform & Corn & Commercial & 80 \\
\hline & North West Bio-Energy Ltd., Unity, SK & Ethanol & Fermentation, Sugar/Starch Platform & Other Grains & Commercial & 25 \\
\hline & Permolex Ltd., Red Deer, AB & Ethanol & Fermentation, Sugar/Starch Platform & Other Grains & Commercial & 45 \\
\hline & $\begin{array}{l}\text { Pound-Maker Agventures Ltd., Lanigan, } \\
\text { SK }\end{array}$ & Ethanol & Fermentation, Sugar/Starch Platform & Other Grains & Commercial & 15 \\
\hline & $\begin{array}{l}\text { Suncor - St. Clair Ethanol Plant, Sarnia, } \\
\text { ON }\end{array}$ & Ethanol & Fermentation, Sugar/Starch Platform & Corn & Commercial & 400 \\
\hline & Terra Grains Fuels Inc., Belle Plaine, SK & Ethanol & Fermentation, Sugar/Starch Platform & Other Grains & Commercial & 150 \\
\hline
\end{tabular}

* Sources: Information obtained and adapted from: Ethanol Producer Magazine; RIC (2017); and personal communications. 


\subsubsection{Ethanol}

First generation ethanol is produced from domestic starch-based feedstocks. In Canada, the primary source of starch is based on the local availability of wheat and corn. In 2016, 3.25 million megatonnes of corn was used for production of fuel ethanol and 0.95 million megatonnes of wheat was processed into ethanol in Canada (Dessureault, 2016). In contrast, over 95\% of the ethanol produced in the United States is made from corn, while wheat is the main starch crop for bioethanol production in Europe (Haefele and Combs, 2017; N'Diaye et al., 2017). Other cereal crops like barley and grain sorghum do not present the economic benefits required for feedstocks for bioethanol production in Canada.

Cereal grains store energy in the endosperm as starch in the form amylose and amylopectin, which are long-chained and branched glucose polymers. The starch content and composition of the wheat and corn kernel are good predictors of ethanol yield (Zhao et al., 2009). Given that the starch is fermented to ethanol, the remaining protein, fiber, and fat content of the grain kernel are important considerations for the distillers grains produced as co-products. Grain quality in terms of moisture, foreign matter, and fermentable substrate can have a significant impact on yield and co-product value ranging from 2.32 gal/bu for poor quality corn grain to 2.93 for the top quality (Haefele and Combs, 2017). Wheat and corn grain composition along with their distillers grains with solubles are presented in Table 4. However, there is considerable compositional variation in distillers grains due to inherent variation in the grain and changes during the processing. Liu (2011) offers an in depth review of the chemical composition of this feed commodity.

Table 4. Average composition of corn and wheat grain, with their respective distillers grains with solubles*.

\begin{tabular}{lllll}
\hline Element & Corn & Corn distillers grains & Wheat & Wheat distillers grains \\
\hline Starch (\%) & $65-72$ & $<4$ & $67-70$ & 2 \\
Protein (\%) & $9-12$ & 29.5 & $12-14$ & 38.5 \\
Fat (\%) & 4.5 & $11.1^{\mathrm{a}}$ & 3 & 5 \\
Fibre (\%) & 2.0 & 7 & 2.6 & 6 \\
\hline
\end{tabular}

${ }^{a}$ Fat content of corn distillers grains produced without crude corn oil extraction.

* Sources: U.S. Grains Council (2012); Monceaux (2017); and Rosentrater (2017).

Although there are differences in the upstream processing of corn and wheat feedstocks, dry-grind fuel ethanol plants share many unit operations. An overview of the dry grind process can be seen in Figure 4. The majority of ethanol plants now use dry milling as opposed to wet milling, which uses water to separate the kernel into starch and water-soluble fractions from the germ to produce purified starch from corn (Kohl, 2017). Table 5 lists the unit operations and their purpose for the processing of corn into ethanol, distillers dried grains with solubles (DDGS), and carbon dioxide, as described by Monceaux (2017).

Many corn ethanol plants have commissioned crude oil extraction technologies to separate the oil from the front-end (upstream) of the plant or from the back-end (downstream) syrup stream. This corn oil can then be used as a separate feed component, or sold as a feedstock for biodiesel or renewable diesel production, while producing a lower crude fat distillers grains (U.S. Grains Council, 2012). The primary use of extracted corn oil is for biodiesel production (Wang et al., 2015). The Energy Information Administration reported that in 2014, 440 million $\mathrm{kg}$ of corn oil was used for biodiesel production in the United States (Wang et al., 2015). This volume is projected to increase to 2.6 billion L by 2022 by the U.S. Environmental Protection Agency, outpacing biodiesel production from soy oil at 2.5 billion L (EPA, 2010).

Canadian plants have mostly operated at full capacity since 2009 , producing an estimated 1,750 million $\mathrm{L}$ in 2016 and expected to increase to 1,775 million L in 2017 (Dessureault, 2016). A summary of commercial and demonstration plants is listed in Table 3. In 2014, ethanol consumption indicated that the federal mandate of $5 \%$ was exceeded in British Columbia (6.3\%), Alberta

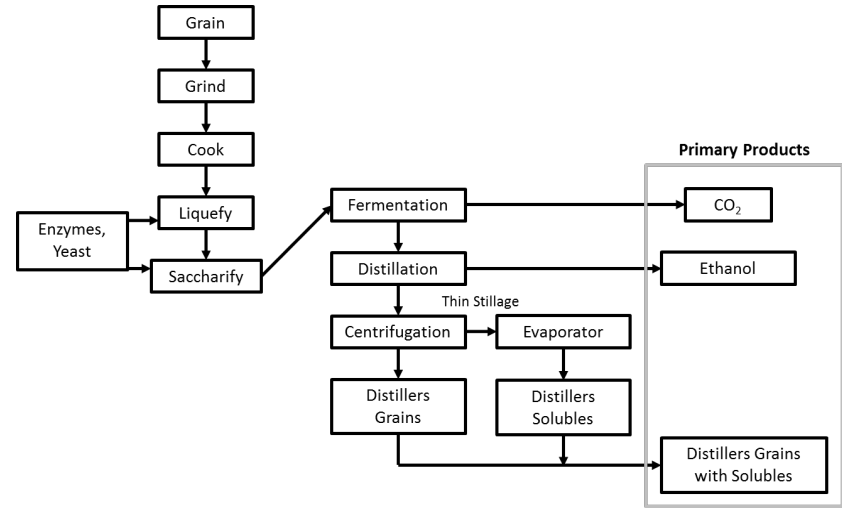

Fig. 4. A basic dry grind grain to ethanol production process (from N'Diaye et al., 2017).

(6.3\%), Saskatchewan (9.0\%), Manitoba (8.0\%), and Ontario $(7.8 \%)$ as a per cent of the gasoline pool (Moorhouse and Wolinetz, 2016). Only Quebec and the Maritimes showed lower blend rates of $4.8 \%$ each. As the ethanol industry in Canada is well established, the majority of efforts are targeting process development for yield and efficiency improvements instead of basic R\&D. New upstream processing technologies such as wet fractionation and fibre separation add features from wet milling to dry-grind ethanol plants, thereby allowing for higher throughput and co-product diversification through cost-effective bolt-on processes (Singh and Kohl, 2017). In 2014, IGPC Ethanol Inc., who operate a fuel ethanol plant located in Aylmer, Ontario, announced it would become the first adopter of ICM's new Fiber Separation Technology ${ }^{\mathrm{TM}}$ (FST) to increase ethanol production and oil recovery (Canadian Biomass, 2014). This technology uses wet fractionation of the slurry upstream of fermentation to remove the corn kernel fibre through a series of counter-current washes and mechanical separation (Singh and Kohl, 2017). The fibre is removed, creating a fermentation feed stream with increased fermentable sugars, and can be recombined with the wet cake post-centrifugation to produce typical DDGS. Alternatively, the wet cake can be isolated and produce a higher protein distillers grains. FST combined with ICM's Selective Milling Technology ${ }^{\mathrm{TM}}$ increased IGPC Ethanol, Inc.'s production capacity from 170 million L of ethanol/year to 200 million L/year (Canadian Biomass, 2014). In 2015, Agriculture and Agri-Food Canada announced through a News Release that it would be supporting IGPC Ethanol Inc.'s adoption of this technology by investing C\$3.7 million as a "repayable contribution through the AgriInnovation Program, a 5 year, up to $\mathrm{C} \$ 698$ million initiative under the Growing Forward 2 policy framework (Agriculture and Agri-Food Canada, 2015)."

In 2017, IGPC Ethanol Inc. announced a C $\$ 120$ million expansion project to double its production capacity from 200 to 400 million Lyear by November 2018 (Sapp, 2017). In August 2017, GreenField Global, Canada's largest ethanol producer, announced it was evaluating an expansion of its biorefinery in Varennes, Quebec, from 170 to 300 million L/year (GreenField Global, 2017). In addition, the integration of the firstgeneration Greenfield ethanol facility in Varennes with a cellulosic ethanol plant using technology from the thermochemical conversion company, Enerkem, is under evaluation. These two significant expansion projects indicate that the Canadian fuel ethanol industry continues to invest in major capital projects. In addition, there are other proposed projects, including Northern Prairie Bioproducts Inc., who are proposing a 522 million L/year plant to be located in Alberta and operate using a sugar/starch platform. There are several smaller-scale plants that operate off the sugar/starch platform that are long-term idled, including Amaizeingly Green LP (corn), 
Table 5.

Unit operations of dry and wet milling processes for the production of ethanol from corn grain

\begin{tabular}{cc}
\hline Dry milling & Wet milling \\
\hline Grain milling & Fractionation \\
\hline Particle size reduction through hammer mills or roller mills to increase surface area & Through steeping, corn is fractionated into its major components: starch, germ, gluten, and fibre \\
\hline Mashing \& Cooking & Cooking \\
\hline $\begin{array}{c}\text { Mixes the corn flour, water and recycle streams into a slurry, which is heated to } ~ \\
\text { gelatinization and enzymatic hydrolysis }\end{array}$ & Heats the starch stream for gelatinization in preparation for enzymatic hydrolysis \\
\hline
\end{tabular}

Liquefaction

Alpha-amylase hydrolyzes the starch into dextrin, reducing the viscosity of the mash

Fermentation

Using gluco-amylase to further hydrolyze the dextrin into glucose monomers and nutrients, yeast (Saccharomyces cerevisiae) convert the fermentable sugars into ethanol and $\mathrm{CO}_{2}$

Distillation \& Dehydration

A beer column, rectifier and side stripper distills ethanol from the fermentation broth, achieving the azeotrope of 95 vol. \%; adsorption of residual water through molecular sieves produces 200 Proof anhydrous fuel ethanol

\section{Centrifugation}

Physical separation of the whole stillage downstream of distillation, producing a wet cake solid fraction and a thin stillage stream that can be further concentrated into a syrup

Not applicable given that the germ and fibre are removed upstream

Evaporation

Concentrates the thin stillage into a soluble-rich stream syrup by removing water through evaporators

Drying

Removes water from the wet cake combined with the syrup stream to produce a distillers dried grains with solubles (DDGS) of approx. $90 \mathrm{wt} \%$ dry solids

Not applicable

Energentium Inc. (waste streams), Future Fuels (other grains), and Noramera Bioenergy Corp (other grains).

$R \& D$ efforts in the first generation ethanol field have been related to feedstock and yeast development. Through the application of transgenic technology, amylase corn was created which contains a heat-activated enzyme that eliminates the need for addition of alpha-amylase (Lanahan et al., 2006). In addition, genetically engineered Saccharomyces cerevisiae with new metabolic pathways producing endogenous glucoamylase and higher ethanol yields are now available from various yeast suppliers (Kohl and Singh, 2017). These new technologies as well as enhanced enzymes are providing incremental gains for fuel ethanol plants, and are indicative of continuing research and development in the industry.

While the academic community in Canada actively contributes to ongoing enhancements of current ethanol processes, it is actively investigating lignocellulosic ethanol production. With regards to first generation substrates, research can be found covering the agricultural feedstock handling (George et al., 2014) and naturally the processing (Görgens et al., 2015). Emphasis has been given to process optimization and continuous fermentation processes (Mustafa et al., 2014; Nanda et al., 2014a). As an alternative to traditional continuous reactor systems, a semi-continuous system dubbed self-cycling and suitable control strategies have been developed (Feng and Lin, 2014; Wang et al., 2017), potentially increasing the overall productivity. More fundamental work has investigated the resistant starch (RS) in distiller's dried grains, a nonconverted starch fraction making up to 18\% of DDGS (Li et al., 2014). The control of reactors using online data such as the redox-potential (Liu et al., 2015) or dissolved carbon dioxide (Feng and Lin, 2014) has been improved, while biotechnological solutions have been proposed to control microbial contaminations in yeast-based processes (Silva and Sauvageau, 2014). Metabolic flux analysis has been applied in order to optimize the conditions for the biocatalysts, particularly with respect to very high gravity fermentations (Cao et al., 2014; Lin and Liu, 2014). It was suggested to co-ferment whey, a by-product of the dairy industry, in first-generation ethanol processes (Jin et al., 2016; Parashar et al., 2016). The dairy waste-stream could replace some of the process water, resulting in cost reductions for the dairy and the ethanol industry. With respect to feedstocks, a large amount of research is dedicated to second generation ethanol production from lignocellulosic biomass. The problem of fermentation inhibitors has been tackled through the development of assays predicting the ability to convert lignocellulosic hydrolysates to ethanol (Wood et al., 2015; Li et al., 2016; Luque et al., 2016). Mitigation strategies were developed through the removal of inhibitors (Gao and Rehmann, 2016; Li et al., 2016; Yu and Christopher, 2017) or through genetic engineering of the microbial strains (Harner et al., 2014 and 2015; Peris et al., 2017). Various pretreatment methods have been investigated with the research being split between agricultural (Agbor et al., 2014; Xiong et al., 2014; Joyce et al., 2015; Luque et al., 2016) and forestry derived feedstocks (Shadbahr et al., 2014; Porth and El-Kassaby, 2015; Tian et al., 2016; Boboescu et al., 2017; Yuan et al., 2017; Yuan and Wen, 2017). Recent Canada-based reviews can be found here (Acharya et al., 2014; Nanda et al., 2014a; Porth and El-Kassaby, 2015; Mupondwa et al., 2017; Volynets et al., 2017). Canadian research covers broad areas from simultaneous saccharification and fermentation (SSF) (Shadbahr et al., 2017; Westman et al., 2017) to gasification followed by syngas fermentation (Acharya et al., 2014; Roy et al., 2015). Other pretreatment methods use ionic liquid-based processes (Tian et al., 2016), super-heated steam (Barchyn and Cenkowski, 2014; Mirhosseini et al., 2016), ammonia fibre expansion (Serate et al., 2015) and thermochemical pretreatment (Luque et al., 2014 and 2016; Suckling et al., 2017). 


\subsubsection{Butanol}

Butanol is currently not produced industrially through fermentation in Canada. Active academic and industrial research is aiming to change that. Multiple biological routes to produce butanol exist, the most common one being through the traditional acetone-butanol-ethanol (ABE) fermentation via chlostridia, as the respective strains effectively utilizes various carbohydrates (Gao and Rehmann, 2014; Gao et al., 2014 and 2016; Nanda et al., 2014b; Sarchami and Rehmann, 2014 and 2015; Khosravanipour Mostafazadeh et al., 2016; Maiti et al., 2016c; Mechmech et al., 2015a, 2015b, and 2016; Levasseur et al., 2017a). Similar feedstocks and pretreatment methods as evaluated above have been used. The biocatalysts have also been enhanced through genetic tools (Bruder et al., 2015; Pyne et al., 2014 and 2016; Nanda et al., 2017).

Recently, the propanediol-butanol-ethanol (PBE) fermentation has gained academic and industrial interest, as the fermentation does not undergo a separate acidogenesis and solventogenesis stage present in $\mathrm{ABE}$ fermentation, and hence is more easily controlled and adaptive to continuous fermentation processes (Johnson et al., 2016). The feedstock for the PBE fermentation is glycerol, and low value streams from the biodiesel industry have been utilized (Johnson and Rehmann, 2016; Sarchami et al., 2016a), while carbohydrates can be co-fed (Regestein et al., 2015; Johnson and Rehmann, 2016; Pyne et al., 2016). The global interest in iso-butanol is not strongly reflected in Canada, with only a single publication between 2013 and 2017 (Ofuonye et al., 2013).

There are several process configurations for butanol production, as shown in Figure $\mathbf{5}$ (Sarchami et al., 2016b). Butanol is a substantially more inhibitory product than ethanol, and product inhibition typically occurs at $15-20 \mathrm{~g} / \mathrm{L}$ (Johnson et al., 2016; Maiti et al., 2016a and b). In-situ product recovery has therefore been investigated (Abdehagh et al., 2014; Sharif Rohani et al., 2015a; Maiti et al., 2016a; Levasseur et al., 2017b) focusing on sorption (Abdehagh et al., 2015 and 2016; Gao and Rehmann, 2016), gas stripping (Sharif Rohani et al., 2015; Abdehagh et al., 2017), and pervaporation (Sharif Rohani et al., 2015; Kießlich et al., 2017). Economic assessments have shown that under current economic conditions, only a continuous process with integrated product recovery will be feasible (Abdi et al., 2016).

\subsection{Thermochemical and chemical}

Thermochemical and chemical processes for the production of liquid biofuels in Canada are less common than biochemical conversion technologies at commercial scale, as first generation ethanol dominates the commercial biofuels landscape. Unlike biochemical processes that predominantly produce alcohols which can be used to satisfy gasoline renewable content regulations, thermochemical processes can be used to produce a wide range of biofuel products. These include not only alcohols, but also drop-in biofuels that are similar to the composition of gasoline and diesel. However, the production on drop-in fuels is lower in TRL than ethanol production. Thermochemical processes involve the application of heat to biomass feedstocks with or without elevated pressure. There may be a catalyst or other chemicals present to participate in the reactions to convert biomass directly into biofuels, fuel intermediates, or building block chemicals for production of fuels.

Thermochemical processes are typically second generation technologies, and feedstocks may include lignocellulosics from a broad variety of sources as well as municipal solid waste. Second generation technologies can potentially offer a more sustainable solution than current commercial biofuel production depending on an array of complex conditions including R\&D, innovation, feedstock availability, market demands, and policies (Whalen et al., 2017). There are several advantages for thermochemical methods of biofuel production over biological methods as listed by Verma et al. (2012), which include higher productivity per unit time, applicability to a wide variety of biomasses, independence to climate conditions due to high temperatures, and high utilization of biomass into product.

Chemical processes are used to produce biodiesel, which are long chain alkyl esters. Production of biodiesel in Canada primarily uses canola and soy oil and, to a lesser extent, recycled vegetable oils and animal fats. Biodiesel production from food crop feedstocks that contain lipids and availability of original oils for production presents a barrier for sustainable renewable fuel option. Biodiesel production from waste feedstocks is also being rapidly explored and commercialized, however, these feedstocks are also limited. Third generation biodiesel is being developed in response to limitations of

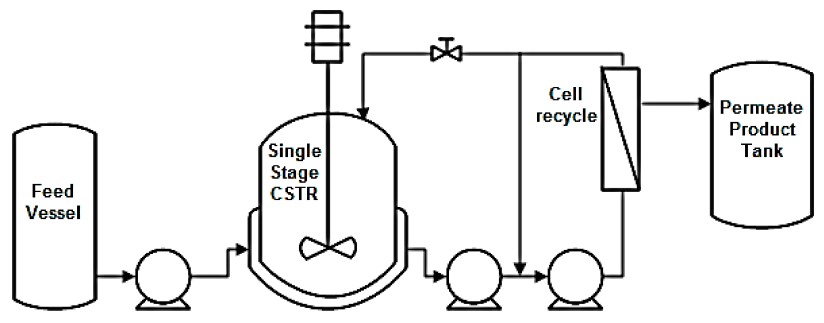

(a)

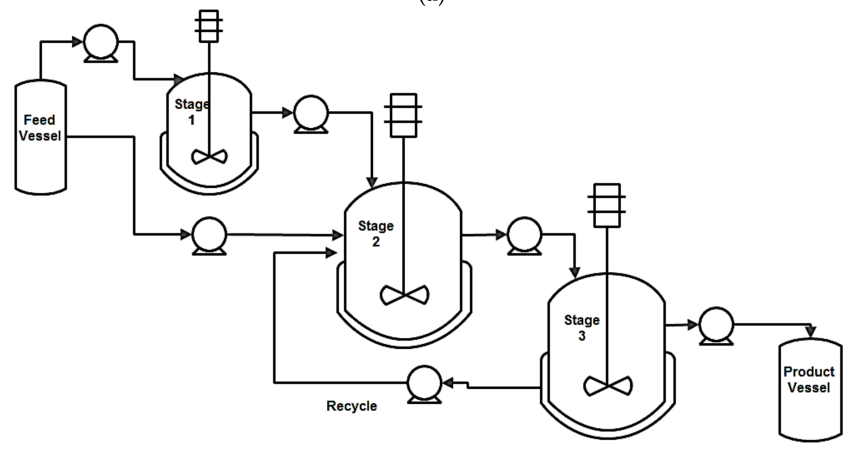

(b)

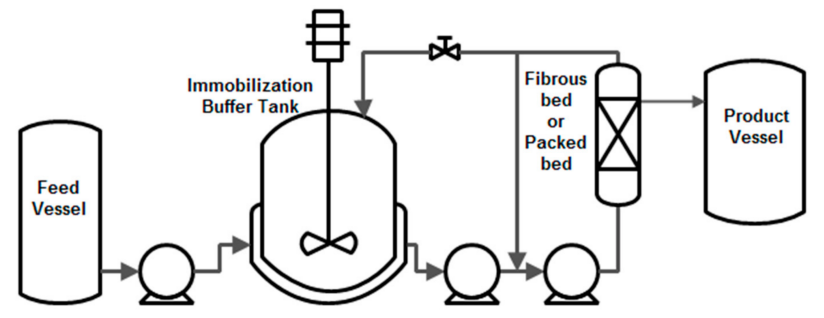

(c)

Fig. 5. (a) Continuous single stage continually stirred tank reactor (CSTR) with cell recycle (b) Continuous multi-staged CSTRs in Series (c) Continuous Biofilm Reactor (from Sarchami et al., 2016).

second generation, which includes microalgae as feedstock; however, reliable production is still under development in Canada (Gumba et al., 2016).

There are many combinations and variations of thermochemical and chemical process pathways that are possible for the production of a variety of liquid biofuel products, which are demonstrated in Figure 6. A description of these processes and, where applicable, their use within the Canadian biofuels industry will be described in the following sections.

\subsubsection{Various grades of bio oil}

Also referred to as biocrude, bio oil in Canada is typically produced through fast flash pyrolysis. The process of pyrolysis has a lengthy history in Canada and an interesting history of earlier bio oil technology development in Canada was written by Hogan (1994) and more recent developments by Meier et al. (2013). Depending on feedstock type, biomass may require drying prior to pyrolysis, as water present increases the heat of vaporization requirements. Time and temperature can be adjusted to favour production proportion of solids, liquids, and gases with fast pyrolysis $\left(500{ }^{\circ} \mathrm{C}\right.$ with a short hot vapour residence time of approximately $1 \mathrm{~s}$ ) favouring bio oil production of $75 \%$ on a dry-feed basis (Bridgwater, 2012). Depending on application, upgrading of fuels may be required as pyrolysis oil contains a complex mixture of organic compounds including alcohols, aldehydes, ketones, phenols, furans, ethers, and sulphur compounds. Physical, chemical, and catalytic methods of upgrading bio oil are reviewed elsewhere (Zhang et al., 2007; Mortensen et al., 2011). 


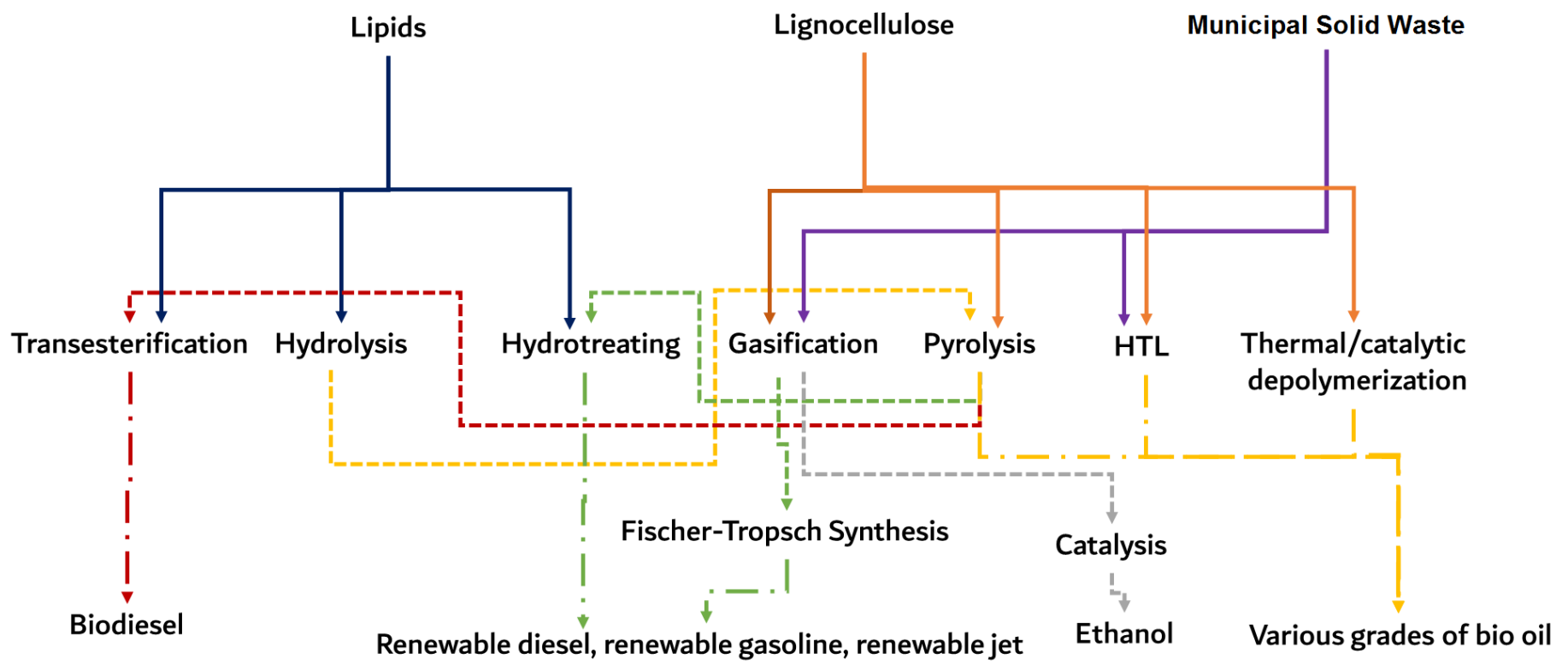

Fig. 6. Overview of simplified, predominant thermochemical and chemical process pathways for production of various liquid biofuels.

There are several other methods of producing biocrude that have lower technology readiness, including hydrothermal liquefaction (HTL). Similar processes include those called depolymerisation via thermal or catalytic treatment or hydrous pyrolysis. HTL operates under severe conditions at temperatures of $250-550{ }^{\circ} \mathrm{C}$ and pressures of $5-25 \mathrm{MPa}$ in the presence of solvents such as ethanol, methanol, acetone, water, 2-propanol, and combinations of the aforementioned (Akhtar and Amin, 2011). The HTL process first hydrolyzes and breaks down biomass into smaller, unstable molecules and the complex chemistry and mechanisms involved in fuel production can be found reviewed elsewhere (Peterson et al., 2008; Toor et al., 2011). A principle feature of HTL is that at the extreme processing conditions, water has unique characteristics and can catalyze depolymerization reactions; therefore, biomass can be converted into fuels without the need for drying. Processing conditions, including temperature, feedstock composition, pressure, particle size, heating rate, solvent density, residence time, and reducing gas, affect the composition and quality of bio oil from HTL (Jindal and Jha, 2015).

Bio oil is an attractive biofuel as it can be produced from a wide range of feedstocks. Pyrolysis can be completed with virtually any biomass with relatively low water content (Bridgwater, 2012). HTL processes have the additional advantage of using feedstocks of high moisture content, which increase the range of applicable feedstocks to green bin compost and MSW. As a key economic feasibly input is biomass proximity, the ability to use many biomass types is a major benefit. Different biomasses can also be blended prior to conversion to expand applicability of pyrolysis and/or HTL to wider geographical areas. However, feedstock type and properties significantly influence processing ability, bio oil yield, and ability to upgrade (Carpenter et al., 2014). This highlights the key limitations of bio oil, which include challenging properties and difficulties in producing a consistent product. Verma et al. (2012) compiled a summary of reported physiochemical characteristics of pyrolysis oil from different biomasses and process conditions and showed that properties can vary drastically between biomass sources, including variations in viscosity from 5 to $>800 \mathrm{cP}$, higher heating values from $<15$ to $>35 \mathrm{MJ} / \mathrm{kg}$, and MW range of 370 to $1000 \mathrm{~g} / \mathrm{mol}$. A thorough review by Mohan et al. (2006) concluded that a critical analysis of the literature in terms of the effect of processes and feedstock on bio oil characteristics is difficult due to the infinite combinations of options of feedstocks and process conditions. These reviews indicate that post production upgrading is needed to standardize bio oil characteristics to expand its applications in Canada as a biofuel beyond use as heating oil. Although bio oil from HTL has improved properties over that from pyrolysis, it also falls short of being a drop-in fuel without upgrading.

Currently in Canada there are several industrial activities in the field of fast pyrolysis for the production of bio oil. Small-scale systems have received some attention, including Agritherm who have developed a mobile fluidized bed pyrolysis unit for conversion of biomass into bio oil and biochar. These mobile units have the capacity of 5 tonnes/d biomass and can generate 3 tonnes/d bio oil and 1.5 tonnes/d of biochar (Agritherm, 2017). ABRI-Tech Inc. is also developing a small-scale transportable fast pyrolysis system that utilizes an auger type pyrolysis reactor. They have 1 tonne/d capacity in the farm and research units and have two larger units being commissioned in Ottawa and Iowa that have the capacity for 50 tonnes/d (ABRI-Tech, 2017). The only commercial-scale plant currently in operation is Ensyn, who utilize a patented Rapid Thermal Process (RTP) to produce pyrolysis oil in Renfrew, Ontario, at a rate of 3 million gallons/year (Ensyn, 2017). In the past, the Sustainable Development Technology Canada (SDTC) contributed $\mathrm{C} \$ 2 \mathrm{M}$ in funding to achieve demonstration of the RTP technology (SDTC, 2017). The pyrolysis oil is utilized as a fuel for heating systems, as well as a feedstock for both fragrances and food flavourings. AE Cote-Nord Bioenergy Canada Inc. is actively completing a project to employ Ensyn's pyrolysis process to convert wood to renewable fuel oil at their saw mill site in Quebec, which has received over C\$27M in funding from the SDTC (SDTC, 2017). A final noteworthy Canadian company is Pyrobiom, located in Quebec, who focus on the design and installation of plants to produce pyrolysis oil and biochar, along with syngas to provide energy to the pyrolysis reactors from woody feedstocks such as bark (Pyrobiom, 2017). Their aim is to establish several industrial-scale plants throughout Quebec's forested regions.

Commercial development of bio oil from HTL has been limited in Canada due to the severe operation conditions required. Conventional barriers to commercialization include the need for expensive alloys to handle corrosive materials, high pressure process equipment and, thus, very high capital investment requirements (Toor et al., 2011). However, there are emerging demonstration HTL and similar technologies that can be 
found in Canada. Steeper Energy Canada Ltd., a company based out of Calgary, $\mathrm{AB}$, is developing plans for commercialization of the "hydrofaction" platform, which produces "hydrofaction oil" using supercritical water to convert wet biomass and organic waste to renewable fuel oil (Steeper Energy, 2017). The product has been demonstrated to have high energy content, low viscosity, and low oxygen content. At the time of writing this manuscript, a company called Cellufuel, located in Brooklyn, Nova Scotia, has successfully operated a demonstration-scale plant for a period of 18 months that produces bio oil that can meet diesel specifications with some post production upgrading. Using wood residual feedstocks and a process of catalytic depolymerisation, their plant has the capacity to operate to produce renewable diesel at $150 \mathrm{~L} / \mathrm{h}$. Operation of the plant is anticipated to resume once solids separation upgrades are completed. The demonstration of this project has been partially funded by the SDTC on the order of C\$2.1 M (SDTC, 2017). The SDTC is also providing funding of over $\mathrm{C} \$ 13 \mathrm{M}$ to a joint venture between Canfor Pulp Products Inc. and Licella Fibre Fuels Ltd. to convert wood residue from Canfor's pulp mills in Prince George to biocrude using a proprietary catalytic hydrothermal reactor (SDTC, 2017).

Various feedstocks and processes are undergoing research and development for advanced bio oil production. Dr. Singh at the National Research Council of Canada in collaboration with CanmetENERGY is undertaking investigations of HTL production from various feedstocks such as green municipal waste and algae using funding from the Program for Energy Research and Development. Universities are also investigating various aspects of HTL production. To name just a few, University of Toronto is researching the production of HTL bio oils from algae (Cheng et al., 2016), University of Western Ontario and Lakehead are exploring HTL of various barks (Feng et al., 2014), and University of Western Ontario is also exploring HTL composition and catalyst selection for wood biomass feedstocks (Nazari et al., 2015). A notable variation on the aforementioned processes includes David Bressler's work at the University of Alberta which involves the production of drop-in hydrocarbon fuels from lipids, including the two step hydrolysis and pyrolysis of waste oil and fats to produce a product that has a 76-80\% organic liquid fraction which is composed of 30\% gasoline-equivalent fraction and 50\% diesel fraction (Asomaning et al., 2014). This proprietary technology that has been investigated at pilot scale in Edmonton is now being used by FORGE Hydrocarbons Corporation who recently received $\mathrm{C} \$ 4.2$ million from the SDTC to construct a production plant that is targeting production of 19 million Lyear of drop-in fuel (SDTC, 2017).

\subsubsection{Liquid fuels produced from syngas}

The liquid fuels produced from thermochemical methods that will be discussed in this section include those that are produced from syngas. Syngas is produced from gasification of biomass via steam (steam reforming), $\mathrm{CO}_{2}$ (dry reforming), or $\mathrm{O}_{2}$ in air or enriched air (partial oxidation). Canada has a rich history in biomass gasification for the production of syngas; as pointed out by Kutney (2017), over 50 biomass gasification ventures have opened up in Canada over the past 50 years. Extensive reviews on gasification processes can be found elsewhere (e.g., Breault, 2010; Ahmad et al., 2016). There are two general pathways for the resulting syngas $\left(\mathrm{H}_{2}, \mathrm{CO}, \mathrm{CH}_{4}, \mathrm{CO}_{2}\right)$ that can be used to produce liquid biofuels; Fisher-Tropsh synthesis (FTS) to produce hydrocarbon fuel and catalysis to produce alcohols. Syngas produced from biomass gasification often has several impurities that require removal prior to synthesis to liquid fuels, including specifications of Suphur and Nitrogen compounds $<1 \mathrm{ppmv}$, Halide compounds and Alkali metals $<10 \mathrm{ppbv}$, and complete removal of ash and soot (Boerringter et al., 2004). In general, quenching is often used to remove solid particles and volatile alkaline metals, various solvents can be used to remove $\mathrm{NH}_{3}$ and $\mathrm{H}_{2} \mathrm{~S}$ by physical absorption, $\mathrm{COS}$ and $\mathrm{HCN}$ can be hydrolyzed to $\mathrm{NH}_{3}$ and $\mathrm{H}_{2} \mathrm{~S}$ to be subsequently removed, and guard beds of activated carbon can be used to remove any remaining $\mathrm{H}_{2} \mathrm{~S}$ (Savage et al., 2010).

For FTS, either Co and Fe catalysts can be used; however, for low $\mathrm{H}_{2} / \mathrm{CO}$ ratios typically obtained from biomass gasification, $\mathrm{Fe}$ has the advantage of boosting the ratio due to the promotion of the water gas shift reaction. More details on advantages and disadvantages of process design and catalyst selection for FTS for biomass derived syngas can be found elsewhere (Savage et al., 2010; Hu et al., 2012). The resulting FT fuel is composed of hydrocarbon chains of various length with the distribution following a superposition of the Anderson-Schulz-Flory distribution, depending upon catalyst type and syngas composition (Patzlaff et al., 1999).
The production of alcohols from syngas can be achieved by first producing methanol from syngas, which can either be used by itself as a fuel (Zhen and Wang, 2015) or as an important chemical building block for other chemicals and fuels (Lavoie et al., 2013). Prior to synthesis of methanol from syngas via conventional technologies, optimization of water gas shift reaction to achieve $\mathrm{H}_{2} / \mathrm{CO}$ ratio of 2 for full conversion to methanol is required. The methanol can then be converted to a variety of liquid fuels. Dimethyl ether (DME) can be produced from methanol via dehydration of methanol, which can be completed in two stages or in a single stage reactor using catalyst for the production of methanol as well as a catalyst $\left(\gamma-\mathrm{Al}_{2} \mathrm{O}_{3}\right.$, silica-alumina, or zeolite) for dehydration (Sai Prasad et al., 2008). The production of ethanol can be achieved from methanol via reaction with carbon monoxide in the presence of a catalyst (Chornet et al. 2011).

There are several advantages of biofuel produced from FTS processes over other biofuels, which include the drop-in nature of the final product. As pointed out by Mabee and Saddler (2010), FTS biofuels have higher energy production yields then ethanol produced thermochemically, as between 2.6-6.9 GJ/tonne and 2.5-3.4 GJ/tonne can be delivered, respectively (Sims et al., 2008). However, these are both typically lower than the production yields obtained from biochemical ethanol production, perhaps because over the last few decades more attention has been paid to R\&D of the biochemical platform (Mabee and Saddler, 2010). A disadvantage of the gasification of biomass to produce syngas for both FTS and ethanol production is the production of tar and particulate matter. There has been extensive work completed on eliminating tar through reactor design (Devi et al., 2003), secondary methods of catalytic reforming using low-cost catalysts (Shen and Yoshikawa, 2013), and clean-up through various methods (Anis and Zainal, 2011). It has been shown on industrialscale that the tar can be reformed and removed; however, the by-product streams from clean-up unit operations are hazardous and often require costly disposal. Recently, work on catalytic oxidation of such tarcontaining by-products, as well as the catalytic activity of the by-product material itself, has been explored to provide an interesting and economically beneficial solution to this problem (Assima et al., 2017).

In Canada, there are currently several activities in the area of syngas production for the subsequent transformation to liquid biofuels and commercial and demonstration scale facilities are listed in Table 3. The most notable plant currently in operation is owned by Enerkem. Enerkem has a demonstration biomass gasification facility located in Westbury, QC, that utilizes the waste portion of decommissioned telephone poles to generate syngas, which is converted to methanol as an intermediate and then to ethanol as a final product (Enerkem, 2017). This demonstration plant has a capacity of 5 million Lyear and testing of other unique feedstocks is completed at this facility. A full-scale biomass waste to energy facility in Edmonton, $\mathrm{AB}$, was recently commissioned that produces methanol and ethanol from syngas utilizing municipal solid waste from the city of Edmonton as a feedstock. This facility has a capacity of 38 million L/year. Enerkem was co-founded by Dr. Esteban Chornet, who developed the technology at the Université de Sherbrooke, where collaborative research to inform process development and improvements are still undertaken. As mentioned previously, Enerkem is licensing its technology globally and is partnering with Greenfield Specialty Alcohols to form Vanerco, which aims to construct a cellulosic ethanol plant on the site of a first generation ethanol plant using Enerkem's technology. Woodland Biofuels Inc. is also producing ethanol from syngas in a demonstration plant located in Sarnia, Ontario. This demonstration plant enables testing of various feedstocks, including waste woods, agriculture wastes, paper wastes, and municipal solid waste and has a capacity of 2 million L/year (Woodland Biofuels Inc., 2017). Liquid fuels through FTS are not currently produced commercially in Canada.

Government support for second generation ethanol production on the thermochemical platform has been significant. Enerkem's Alberta Biofuels Project to utilize sorted municipal solid waste to produce ethanol and methanol as a coproduct, has been granted over $\mathrm{C} \$ 10$ million from the SD tech fund, as well as over $\mathrm{C} \$ 63$ million from the NextGen Biofuels fund (SDTC, 2017). In addition, ecoENERGY program through NRCan contributed to a project exploring the production of drop-in fuels from syngas produced from municipal solid waste, which was led by Enerkem. Syngas was used in the production of DME and subsequently oligomerized 
olefins. It was determined that catalyst deactivation occurred rapidly and integration with pre-existing biomass gasification plants is not economically favourable at this time (NRCan, 2017). The use of DME to replace diesel fuel is also of interest to Transport Canada, as they recently retained the National Research Council to investigate the production, distribution, handling, and use of DME in road vehicles through the ecoTECHNOLOGY for Vehicles program (Transport Canada, 2017). Woodland Biofuels has also received funding from the SDTC (> C \$4 million) for development of a catalyzed pressure reduction $\left(\mathrm{CPR}^{\mathrm{TM}}\right)$ technology (SDTC, 2017), which involves steam gasification, syngas cleanup and conditioning, conversion of syngas to methanol, carbonylation of methanol to produce methyl acetate, and hydrogenation of methyl acetate for the production of ethanol (Woodland Biofuels Inc., 2017).

There are several universities in Canada working on aspects of gasification, which are important for optimization of syngas production for both alcohols and FTS fuels. In addition, various new feedstocks are being explored. The University of Calgary in collaboration with McGill University are looking at catalytic gasification of biosolids (Arnold et al., 2017) while University of Saskatchewan and York University are looking at gasification of horse manure, fruit wastes, and agro-food residues using supercritical water gasification (Nanda et al., 2016). Supercritical gasification is another area that is receiving attention at the academic level in Canada at several institutions, including the University of Saskatchewan (Kang et al., 2016) and University of Western Ontario (Behnia et al., 2016), as the use of supercritical water increases diffusion coefficients and reaction rates in the gasifier. Finally, low cost catalysts are being explored at University of British Columbia, such as Fenton's reagent combined with red mud for the secondary cracking reformation of tar and char gasification (Yang et al., 2017). The aforementioned research is only a sample of research on syngas production for biofuel production and second generation technologies will likely move to higher TRLs in the coming years.

\subsubsection{Hydrogenation derived renewable diesel}

Hydrogenation derived renewable diesel, or HDRD, is utilized in Canada to meet regulations outlined in Table 1 , as 149 million $\mathrm{L}$ was blended into diesel in 2015 and its utilization has tripled since 2010 (Wolinetz and Hein, 2017). Renewable diesel that will be discussed in this section refers to biofuel produced via the process of hydrogenation of plant or animal fats, algae or bio oil. This product goes by many names, including renewable diesel, hydrobiodiesel, renewable synthetic fuel, and green diesel to name a few (Lapuerta et al., 2011). Renewable diesel is produced via conventional hydrotreating catalysis which involves breaking down triglycerides into intermediates and then converting them to alkanes. Details of the conversion pathway of vegetable oil to alkanes, as well as conditions of conventional hydrotreating catalysis for renewable diesel production can be found elsewhere (Huber et al., 2007). The by-products that are formed during production of renewable diesel are propane, $\mathrm{CO}$, and $\mathrm{CO}_{2}$. Plant or animal fats or algae oil can be used directly as feedstocks for hydrotreating. Lignocellulosic feedstocks must first be converted to bio oil via pyrolysis or hydrothermal treatment and then subsequently hydrotreated and upgraded to make renewable diesel (Patel and Kumar, 2016).

There are advantages to the production and use of HDRD fuel. Since conventional equipment is utilized for HDRD processing, it can be integrated into pre-existing refinery processes. HDRD can be produced from a wider range of feedstocks than biodiesel, due to free fatty acid content not being a concern during processing and the potential to use lignocellulosic materials (Lambert, 2012a). Despite the advantages, currently the HDRD utilized in Canada is $100 \%$ imported and there are no industrial-scale processes in operation. A study by Lambert (2012b) found high cost was a barrier for the use of HDRD and access to new plants in North America to create a hike in supply and a corresponding reduction in price would allow HDRD to be adopted in Canada more ubiquitously. Techno economic analysis estimates that, considering an optimized plant scale in Western Canada, HDRD can be produced from canola oil at C $\$ 1.09 / \mathrm{L}$ (Miller and Kumar, 2014). Since the 2\% regulation can be satisfied by the cheaper option of biodiesel without any adverse outcomes, increased blending requirements may have to be implemented before HDRD production is advantageous in Canada to make up for biodiesel's chemical property shortcomings.

\subsubsection{Biodiesel}

After ethanol, the second highest biofuel produced in Canada is biodiesel. It accounts for over $75 \%$ of the renewable fuel used to meet diesel regulations listed in Table 1 (Wolinetz and Hein, 2017). It is the only biofuel being used to satisfy the diesel requirement that is produced within Canada and is not $100 \%$ imported. First generation biodiesel is produced using edible vegetable oil feedstocks, whereas second generation technologies are being used to produce biodiesel from non-food feedstocks including waste plant and animal fats. More than $70 \%$ of total biodiesel produced in Canada comes from operations that utilize edible oils (canola and soy) exclusively. Biodiesel is composed of a mixture of long-chain monoalkylic esters from fatty acids and can be produced via pyrolysis, microemulsion, dilution, or transesterification and details on these processes can be found in the literature (e.g., Singh and Singh, 2010 Atabani et al., 2012). Transesterification is by far the most popular method as it is most cost effective and produces a reasonably consistent product. The production of first generation biodiesel can generally be described as the transesterification of triglycerides in fats and oils by reaction with a short chain alcohol (typically methanol) in the presence of a catalyst (typically $\mathrm{NaOH}$ ), followed by purification. A by-product of this process is glycerol, which can be recovered, as well as other components such as soap, alcohol, and water. Inedible oils typically have a larger level of free fatty acids, which are not desirable as they promote soap formation and lower yields (Koh and Mohd. Ghazi, 2011). This can be overcome by use of processes such as acid-catalyzed transesterification, enzyme catalyzed transesterification, and the non-catalyzed Biox transesterification process (Math et al., 2010). Third generation biodiesel is produced from microalgae, which involves cultivation of algae typically in photobioreactors, extraction of oils, and then subsequent transesterification. This process is still in the development stages, but attracts substantial attention due to its high yield potential. Compared to conventional crop feedstocks, microalgae have high growth rates, productivity, and oil content. For example, microalgae have the potential to produce an oil yield that is 250 times the amount produced from soybean feedstocks (Atabani et al., 2012). Third generation biodiesel production from algae does have several theoretical advantages to produce larger volumes economically, however, several process hurdles that must be overcome include costly nutrient requirements, as noted by Aghbashlo and Demirbas (2016) such as costly nutrient requirements which must be overcome. There are many variations for first generation production processes, as well as additional and/or alternative requirements for preprocessing of second and third generation processes, which are reviewed throughout the literature (Ma and Hanna, 1999; Gerpen, 2005; Bhuiya et al., 2014; Scaife et al., 2015; Tabatabaei et al., 2015).

There are several active biodiesel facilities in Canada, as listed in Table 3. The agricultural giant Archer Daniels Midland is the largest producer of biodiesel in Canada and the plant located in Lloydminster BC has a capacity of 265 million Lyear from canola oil (RIC, 2017). Atlantic biodiesel is the next largest producer and operates under kosher status, which allows them to produce kosher glycerol as value added by-product (Atlantic Biodiesel, 2017). BIOX is another large producer of biodiesel and has a history of development within Canada. The BIOX process involves the use of a cosolvent phase to improve the rate of conversion of oil into ester by overcoming the issue of low solubility of methanol in oil, which was developed at the University of Toronto by Professor David Boocock (Boocock et al., 1996). There are several operations currently active, typically at smaller scales, that utilize inedible feedstocks, such as yellow grease and animal fats, which can also be seen in Table 3 . This includes the Cowichan Biodiesel Coop, which uses the clever marketing of their biodiesel as a "micro-brew you put in your gas tank" (Cowichan Biodiesel Coop, 2017). The ecoENERGY program funded by the Canadian government has provided a boost to the biodiesel industry, as this initiative provides operating incentives to producers of renewable fuels, which decline in rate from 2008 to the completion of the program in 2017. For 2016-2017, an incentive of C $\$ 0.04 / \mathrm{L}$ is available for biodiesel producers (NRCan, 2016). Despite pressure from the biodiesel industry in Canada for a continuation of the program, the subsidy program was phased out as 
planned after total spending of C\$ $1 \mathrm{M}$ on both ethanol and biodiesel (McCarthy, 2013).

There are pilot and demonstration scale activities for biodiesel production throughout Canada. Several of these activities have been funded through the SDTC through either SD Tech Fund or through the NextGen Biofuels Fund that supports first-of-kind demonstration facilities for the production of nextgeneration renewable fuels. SBI Bioenergy, located in Edmonton, AB, received funding for the development of an innovative, single step biodiesel reactor that eliminates $62 \%$ of the capital costs and $12 \%$ of the operating costs compared to current biodiesel production (SBI Bioenergy, 2017). This process involves the use of novel heterogeneous catalysts to make an efficient, scalable operation. SBI produces drop-in renewable diesel, jet and gasoline using biodiesel as a feedstock. At the time of writing this review, SBI Bioenergy Inc., located in Edmonton, AB, has just announced that Royal Dutch Shell obtained exclusive development and licensing rights for their technology and they will work together to demonstrate the technology in preparation for commercial scale-up (CNW, 2017). When up and running, this facility is targeting a capacity of 10 million L/year. In the past, SDTC funds have also been provided to such companies as Milligan to develop a system for valorization of distressed canola seed (C\$7 M) and BIOX for development of a cost effective, optimized process (C\$5 M) (SDTC, 2017).

There are numerous Canadian companies involved in $R \& D$ and pilot projects developing algae technologies platforms for biodiesel production. For example, Pond Technologies, located in Markham, ON, are producing biodiesel and jet fuel from algae on pilot scale, along with several other bioproducts including lubricants (Pond Technologies, 2017). Government investments have also been made, such as through the National Research Council's flagship program for algal carbon capture. However, biodiesel is only one of the wide-range of bioproducts targeted by the flagship program. The SDTC is currently funding projects in this area as well, including MARA Renewables Corporation that is utilizing a heterophilic algae with high productivity and plan to build a demonstration facility for the production of cost effective algae oil (Mara Renewables Corporation, 2017). Several universities are exploring production of biodiesel from microalgae, including lifecycle analysis of microalgae technologies (Collotta et al., 2017) and cultivation of microalgae from wastes streams (Ge et al., 2017) at Queen's University. Nevertheless, a thorough review by Scaife et al. (2015) identifies knowledge gaps in the economic case for third generation technologies and identifies funding limitations for processes that utilize feedstocks other than agricultural in Canada, such as microalgal processes.

\section{Transportation applications}

Since 2010, the Government of Canada and its provincial counterparts have enacted Renewable Fuel and Low Carbon Fuel Standards to promote the adoption of renewable fuels. The motivation for these regulations is to reduce GHG emissions by the transportation sector. According to the most recent data (Wolinetz and Hein, 2017), the volume of ethanol that was blended with gasoline and consumed in 2015 was 2,819 million L. In contrast, the volumes of biodiesel and HDRD that were blended with diesel fuel and consumed in 2015 were 474 and 148 million L, respectively. Sections 4.1 and 4.2 will focus on the utilization of ethanol and biodiesel/HDRD by the transportation sector, respectively.

\subsection{Ethanol}

Fuel ethanol is ethanol $\left(\mathrm{C}_{2} \mathrm{H}_{5} \mathrm{OH}\right)$ that has been denatured with at least $2 \%$ by volume of gasoline to render it undrinkable. Ethanol is blended with gasoline for use in automotive spark ignition (SI) engines. Ethanol has a higher octane number than gasoline, which makes it a premium blending component in some regards. However, denatured ethanol contains approximately $30 \%$ less energy on a volumetric basis than gasoline. The most common blend found at fuel retailers in Canada is E10, which contains up to 10\% denatured ethanol by volume. New vehicles sold in North America are designed to work with E10. There are also a few fuel retailers that sell E85, which contains up to $85 \%$ of denatured ethanol by volume. E85 is only suitable for use in a flexible-fuel vehicle (FFV).

The movement of large quantities of petroleum products from refineries to distribution terminals is most cost-effectively accomplished through pipelines in Canada (M.J. Ervin and Associates, 2007). Marine, rail, and truck transportation are also used to transport petroleum products in areas not served by pipelines. Ethanol is generally not transported in petroleum product pipelines since ethanol absorbs water that is found in pipelines, which would lead to product quality issues in the ethanol-gasoline blend and other petroleum co-products transported in the pipeline. Moreover, the small volumes of ethanol consumed in Canada do not warrant pipeline transport at the present time. As a result, ethanol is transported by marine, rail, or truck transportation to a petroleum distribution terminal and typically splash-blended with gasoline in the tanker truck that transports the fuel to the fueling station.

Volatility is an important property of fuels used in automotive SI engines. Fuel volatility must be high enough to provide adequate engine cold starting and driveability performance, while avoiding the formation of flammable air-fuel mixtures in the headspace above the fuel in the fuel tank. It also must not be too high in order to minimize evaporative emissions during refilling operations and from the vehicle's fuel system. Volatility is quantified in terms of the fuel vapour pressure.

In Canada, the composition of automotive ethanol fuel (E50-E85) (CAN/CGSB-3.512-2013, 2013) is seasonally adjusted based upon climatic history to meet the vapour pressure specification. The composition of E85 varies from $85 \%$ down to $50 \%$ denatured ethanol by volume under warm and cold climatic conditions, respectively. The standard addresses four volatility classes where the denatured fuel ethanol and gasoline of the fuel blend are seasonally adjusted to achieve the required minimum fuel vapour pressure.

The minimum vapour pressure limit specified for automotive SI gasoline minimizes the potential for formation of flammable fuel-air mixtures in the headspace of vehicle fuel tanks. At low ethanol blending levels, the vapour pressure of an ethanol-gasoline blend is higher than that of gasoline, while substantial decreases in vapour pressure occur at higher blending levels due to the lower vapour pressure of ethanol compared to gasoline. As a result, the volume percent of gasoline in E85 must be increased during the winter months to maintain adequate volatility of the ethanol fuel blend.

An experimental study of vapour space flammability of E10 and E85 winter automotive fuels was investigated in a specially-designed apparatus that measures the upper temperature limit of flammability in the headspace above gasoline and ethanol/gasoline blends with a fuel fill level of 5\%. There is a risk that a fuel tank fire could occur during refueling if a static electricity discharge were to occur close to a flammable fuel vapour-air mixture in the headspace. The test results showed that the E10 field samples during the winter months did not produce flammable mixtures unless the ambient temperature was below $-30{ }^{\circ} \mathrm{C}$ to $-35{ }^{\circ} \mathrm{C}$, whereas the E85 field samples collected with about $55 \%$ ethanol did not produce flammable mixtures at $-30{ }^{\circ} \mathrm{C}$ (Gardiner, 2017).

It is very difficult to generalize the effect of ethanol content on automotive SI engine performance and emissions. Firstly, fuel producers may compensate for the high octane number of the ethanol by blending lower octane number gasoline into the ethanol blends. Secondly, advanced SI engines may be able to operate at higher compression ratios and achieve higher fuel conversion efficiencies on ethanol blends with a higher octane number, while more conventional SI engines will not take advantage of an ethanol blend with a higher octane number. Thirdly, modern automotive SI engines are equipped with a closed-loop control system that utilizes an oxygen sensor in the engine exhaust to ensure that a stoichiometric ratio of fuel and air delivered to the combustion chamber. These engines will automatically reduce the intake air flow to compensate for the oxygen in the ethanol. Older automotive SI engines without a closed loop system or engines with a carburetor are not able to adjust the air-fuel ratio and will run improperly.

Environment Canada measured the emissions from three multi-port fuel injected (MPFI) vehicles and one gasoline direct injection vehicle operated with a base gasoline fuel, E10 blends that were tailor and splash blended and an E20 fuel that was tailor-blended. They also reported emission measurements of four FFV operated on E85 and certification gasoline. The results of low blend ethanol gasoline suggest that up to E20 blends can lead to statistically significant reductions in EPA Federal Test Procedure composite emissions of $\mathrm{CO}$, a statistically significant increase in NOx and acetaldehyde emissions, and no change in NMHC emissions. The E85 blends reduced NOx and NMHC emissions by $45 \%$ and $48 \%$, respectively, 
compared to gasoline. However, large increases in formaldehyde (74\%) and acetaldehyde (2540\%) emissions were reported (Graham et al., 2008).

\subsection{Biodiesel and $H D R D$}

Biodiesel is currently the most cost-effective alternative to meet the $2 \%$ Federal Regulation for renewable content in diesel fuel. Fuel suppliers typically meet the Regulation by blending 5\% biodiesel (B5) into diesel fuel during the summer months since B5 blends are generally warranted by diesel engine manufacturers as long as the fuel meets appropriate quality standards. In Canada, the specifications for B1-B5 and B6-B20 biodiesel blends are CAN/CGSB-3.520 and CAN/CGSB-3.522, respectively. The biodiesel (B100) component for blending in middle distillate fuels must comply with CAN/CGSB-3.524.

Biodiesel has some technical advantages compared to ultra-low sulphur diesel (ULSD) fuel, including superior auto-ignition properties (high cetane number), the absence of sulphur and aromatic compounds, and reduced ecological impacts in aqueous spills (Hollebone et al., 2008). It also generally reduces regulated emissions, except for NOx (Agarwal, 2007). Biodiesel has the advantage of dramatically improving lubricity when blended with ULSD fuel due to contaminant species such as free fatty acids and monoacylglycerols, which eliminates the requirement for lubricity improver additives (Knothe and Steidley, 2005).

Biodiesel has several significant technical challenges, particularly with respect to its utilization in cold weather climates, such as Canada. Firstly, biodiesel has relatively poor cold flow properties, which makes it a less desirable diesel blending component during the winter months. Secondly, biodiesel is generally not transported in petroleum product pipelines since it has the potential to contaminate other petroleum co-products, notably jet fuel. Similar to ethanol, biodiesel will absorb water that is present in the pipelines. Thus, the existing fuel distribution infrastructure needs to be modified to accommodate biodiesel. Thirdly, biodiesel has poor thermal stability compared to ULSD fuel. This may lead to fuel fouling issues in the fuel injection systems of modern diesel engines (Amara et al., 2014). Fourthly, biodiesel typically increases oxides of nitrogen emissions slightly (Hoekman and Robbins, 2012). Lastly, biodiesel (B100) has approximately $8 \%$ lower energy content on a volumetric basis than ULSD fuel.

HDRD is the second blending component option for fuel suppliers to meet the $2 \%$ Federal Regulation for renewable content in diesel fuel. HDRD is generally produced by hydrotreating yellow grease, animal tallow, or vegetable oils to remove the oxygen, which results in a hydrocarbon product with much closer chemical composition to ULSD fuel than biodiesel (Stumborg et al., 1996). As a result, HDRD can be easily integrated into existing fuel infrastructure in North America. Due to the paraffinic nature of HDRD, it is amenable to adjustment of the cold flow properties in a refinery isomerization unit, which is another major advantage of HDRD compared to biodiesel. Excellent cold weather properties are extremely important in cold weather climates such as Canada. HDRD has a similar energy content to diesel fuel on a mass basis, typically $44 \mathrm{MJ} / \mathrm{kg}$ (Hoekman et al., 2009). The major disadvantage of HDRD from a Canadian perspective is that it is an imported product, which makes it a more costly option than biodiesel (Lambert, 2012a). Secondly, it should be noted that care must still be taken when blending higher levels of HDRD in diesel fuel to ensure that the fuel blend is fit-for-purpose. HDRD is not a "drop-in" diesel fuel in the strict sense as it has slightly different properties and does not contain all of the hydrocarbon classes.

The BIOBUS project (BIOBUS Committee, 2003) was a joint effort by the Canadian Renewable Fuels Association, the Fédération des producteurs de cultures commerciales du Québec, Rothsay/Laurenco, and the Société de transport de Montréal. Through this project, a total of 550,000 L of B100 were consumed by 155 buses at the STM's Frontenac terminal between March 2002 and March 2003. B100 provided by Rothsay/Laurenco was blended with CAN/CGSB-3.517 diesel fuel (Type A during the winter months) to produce B5 and B20 biofuel blends. The study used biodiesel derived from used cooking oil $(48 \%)$, vegetable oil $(28 \%)$, and animal fat $(24 \%)$ feedstock. The BIOBUS project successfully demonstrated the utilization of B20 during the winter months at ambient temperatures down to $-30^{\circ} \mathrm{C}$. However, this was mainly due to having the STM buses parked in a garage heated to $15^{\circ} \mathrm{C}$ when they were not in use. Special care was taken to heat the B100 prior to blending with diesel fuel during the winter months. In addition, strict procedures for multi-step filtering to prevent clogging of refuelling pump filters and bus system filters were developed. The B5 and B20 blends were filtered after blending using the same pore size as the finest filters in the bus fleet. The study noted that there were additional challenges when blending biodiesel derived from animal fat with cold diesel fuel as wax crystals formed clumps above the cloud point of the biodiesel. Lastly, the BIOBUS project team noted that care must be taken in switching from B5 to B20 blends as the release of deposits on tank walls led to filter clogging on buses equipped with $10 \mu \mathrm{m}$ filters.

Environment Canada (Souligny et al., 2004) measured the performance and emissions of two representative diesel engines from the BIOBUS project with the same biodiesel blends. The engines were model year 1998 and 2000, four-stroke, $250-\mathrm{hp}(186 \mathrm{~kW})$ Cummins diesel engines. The older engine was equipped with a mechanical fuel injection pump, while the newer engine had a computer-controlled electronic fuel injection system. The engines were both tested with B5 and B20 blends with the STM diesel fuel. The engines were operated according to the U.S. EPA heavy-duty, transient test procedure found in the Code of Federal Regulations (CFR) 40 Part 86. The NOx and PM emissions from the engine with mechanical fuel injection were roughly double those of the electronically-controlled engine. The carbon monoxide (CO), hydrocarbon $(\mathrm{HC})$, and particulate matter (PM) emissions from the mechanically-controlled and electronicallycontrolled engines were reduced by 10 and $25 \%, 22$ and $28 \%$, and 24 and $13 \%$ with the B20 blends compared to the STM diesel fuel, respectively. There were no significant NOx emission and fuel consumption differences between the biodiesel blends and the STM diesel fuel. Biodiesel blends were also found to reduce unburned hydrocarbon, carbon monoxide, and particulate matter emissions from diesel engines in a subsequent study (Agarwal, 2007).

As stated previously, biodiesel has the advantage of dramatically improving lubricity when blended with ULSD fuel. The Saskatoon BioBus project studied the long term effects of a B5 blend derived from canola oil on fuel economy and engine wear of four City of Saskatoon buses over a two-year period. Two of the buses were equipped with Detroit Diesel 6V92 two-stroke engines, while the other two buses had Detroit Diesel D-50 four-stroke engines. The four buses were driven more than $400,000 \mathrm{~km}$ over the two-year period, with each bus using B5 one year and low sulphur diesel fuel the other year. Engine wear was monitored by collecting weekly engine crankcase oil samples and analyzing the samples using inductively coupled plasma spectroscopy (ICPS), ferrography, and oil filter debris analysis. The study showed that the B5 blends had better lubricity, which reduced engine wear rates by 7.8 to $23.4 \%$ and improved fuel economy by 2.7 to $4.3 \%$ in city driving (Munshaw and Hertz, 2006).

A number of laboratory studies and demonstration projects have been completed to de-risk the utilization of both biodiesel and HDRD for transportation applications. The Renewable Diesel Characterization Study (RDCS) involved laboratory testing to characterize renewable options for meeting the Renewable Fuels Standard. This laboratory study was a predecessor to the subsequent Alberta Renewable Diesel Demonstration (ARDD) project. The RDCS project involved the characterization of renewable diesel fuel blending components, especially their low temperature properties, and renewable diesel fuel blends $(2,5$, and $10 \%$ by volume). The most promising biodiesel and HDRD blending components were blended with winter-grade ULSD fuels from several fuel suppliers and tested against the CAN/CGSB-3.520 specification. The study concluded that it was possible to create low level renewable blends suitable for use in Canadian winter conditions. However, renewable diesel blending components with higher cloud points may require the addition of ultra-low sulphur kerosene or other refining adjustments to meet the CGSB cloud point targets (Rilett and Gagnon, 2008).

The aim of the ARDD project was to provide information and operating experience regarding the renewable blending component options to stakeholders in the diesel fuel industry. The project involved operating a total of 75 vehicles on biodiesel and HDRD blends with ULSD fuel. During the winter months, $2 \%$ renewable blending components were used, while $5 \%$ renewable blending components were used during the spring and summer months. The renewable blends were produced by blending the appropriate renewable content with seasonal diesel and ultra-low sulphur kerosene (CAN/CGSB 3.517 Type A) fuel. For the biodiesel blends, 21$43 \%$ kerosene was required to meet the seasonal cloud point specification in CAN/CGSB-3.520; whereas, 8-15\% kerosene was needed for the HDRD 
blends. The renewable blending component storage tanks and pipes were insulated and heated. The ARDD demonstrated that $2 \%$ blends by volume of canola methyl ester and HDRD are fully operable in winter conditions when cloud points are adjusted to meet CAN/CGSB specifications. Once blended, all test fuel in the ARDD performed adequately in existing handling, storage, and usage environments (Climate Change Central, 2009).

In 2008, the Government of Canada launched the National Renewable Diesel Demonstration Initiative (NRDDI) to address remaining industry and end-user concerns about blending 2\% renewable components in diesel fuel. A total of seven projects were delivered by stakeholders with funding assistance provided by the NRDDI in advance of enacting new fuel regulations (Renewable Fuels Regulations, 2010). The initiative included projects in both on-road transportation and off-road sectors to demonstrate how renewable diesel fuel will perform in Canadian conditions. Biodiesel was a primary focus of this program due to concerns about its low temperature properties. The offroad projects investigated the impact of renewable diesel on railway locomotive, construction and forest equipment, generator set, and agricultural equipment operations. In general, these studies investigated B5 blends and reported that no major issues were encountered during the demonstration projects (NRCan, 2010).

NRDDI provided funding to Imperial Oil to investigate low temperature storage, operability, and thermal/oxidative storage stability of biodiesel, as well as the utilization of $10 \%$ biodiesel blends in furnaces. The objective of the low temperature tests was to investigate the effects of saturated mono-glycerides (SMG) on filters in fuel handling systems and heavy-duty diesel trucks. The study showed that precipitates enriched in SMG formed in the B5 and B20 blends after ten days of storage at $2-4{ }^{\circ} \mathrm{C}$ above the cloud point. The filter blocking tendency (FBT) test (ASTM D2068-08) correlated well with the SMG content of the fuel. The heavy-duty diesel truck tests involved spiking a B5 biodiesel fuel spiked with three levels of SMG. The fuel delivery system was negatively impacted by the phase separation of spiked SMG at $-16{ }^{\circ} \mathrm{C}$, well above its $-26^{\circ} \mathrm{C}$ cloud point. The data suggests that the renewable diesel blend should have a FBT in the 1 to 1.4 range similar to conventional diesel fuels (Imperial Oil, 2009).

The Royal Military College conducted a biodiesel stability study over a tenmonth period with NRDDI funding. The biofuels were blended using a ULSD fuel and three biodiesels (B100) derived from animal tallow, yellow grease, and canola oil. Three sets of ULSD, B2, B5, B10, B20, and B100 blends were prepared and stored in one-liter brown bottles. Two of the sets were stored in a refrigerator and heated oven at $5{ }^{\circ}$ and $40{ }^{\circ} \mathrm{C}$, while the third set was alternated on a daily basis between the refrigerator and the oven. The acid numbers (ASTM D664) of the test fuel samples were measured on a monthly basis. The B100 blending components showed the largest increase in acid number over a six-month period. The largest increases in acid number were for the B100 biodiesels derived from animal tallow and yellow grease stored at $40{ }^{\circ} \mathrm{C}$. All blends between B2 and B20 were much more stable than the B100 samples and remained in the range of $0.1-0.3 \mathrm{mg} \mathrm{KOH} / \mathrm{g}$, which is below the $0.5 \mathrm{mg} \mathrm{KOH} / \mathrm{g}$ standard in ASTM D6751. Accelerated oxidation stability was also measured according to EN14112 (Rancimat). The Rancimat test involves bubbling air through a sample at $110^{\circ} \mathrm{C}$. The biodiesel blends derived from tallow were the most stable, followed by those derived from canola oil and yellow grease. The low level biodiesel blends were more stable than the base biodiesel blending components.

In 2012, a Canadian study reported that fuel suppliers require less additional storage and blending infrastructure to meet the Renewable Fuel Standard with HDRD than with biodiesel. HDRD also requires less kerosene to meet the cloud point specifications during the winter months (Lambert, 2012a). In a separate study, the same author reported on the investments made to refineries, terminals, and offloading facilities to accommodate the Renewable Fuel Standard, including the purchase or cleaning of tanks and equipment for blending. The author indicated that most refiners would ideally choose HDRD due to its favourable physical properties, the reliability of existing suppliers, and the fact that most HDRD production plants are relatively large-scale and can reliably provide the required volumes (Lambert, 2012b). HDRD is also a promising renewable blending component option for realizing GHG emission reductions in Canada. It has been estimated from an LCA of hypothetical $\mathrm{HDRD}$ production in Canada that well-to-wheel $\mathrm{GHG} \mathrm{CO}_{2}$ emissions per MJ would be reduced by $53.4-61.1 \%$ compared to fossil-based diesel fuel (Wong et al., 2016).

\section{Future prospects}

It has been established that the strategy for meeting GHG reduction targets up until 2060 will include efficiency improvements, electrification, and bioenergy. Electrification is expected to increase its role in transportation; however, biofuels are expected to be a significant and necessary component of movement to a low-carbon economy including vehicles and particularly for aviation and heavy-duty trucks (International Energy Agency, 2017). The pressing question is: how can bioenergy and biofuels be adopted in the mainstream? One rational, systematic approach includes the deployment and expanded use of mature technologies, the development of new technologies, increasing feedstock supply and availability, and building investment pipelines including policy implementation and international collaboration (Brown, 2017).

The role of policy in boosting the biofuels industry has been shown to be successful (Wolinetz and Hein, 2017), which indicates that it is a tool that can shape the direction of the industry in the future. Boosts have been provided primarily for first generation biofuels (ethanol and biodiesel) through both policies such as the RFS and programs such as ecoENERGY. However, as discussed in the sections above, there may be limitations regarding compatibility and utilization of higher blends of these biofuels in Canada. This will become an issue if policy takes the shape of increasing renewable component blend requirements. However, solutions are being developed to handle higher blending requirements; for example, processes are currently being developed to improve the cold flow properties of biodiesel. One example involves the use of heterogeneous catalysis to perform dehydrogenation, hydrocracking, and hydroisomerisation to improve biodiesel composition, which seems to offer a potential solution to improve the cold flow properties of biodiesel (Anwar and Garforth, 2016). However, the oxidative stability tends to decrease in biodiesel that has improved cold flow properties. First generation technologies may also struggle with policies such as LCFS due to carbon involved with crop production, natural gas usage for plant operation, and transportation.

Regulations and policies that do not target particular feedstocks and/or products, but instead target carbon intensity, may be advantageous to the ultimate goal of GHG reduction. Advanced second and third generation technologies may provide reduced overall carbon output and requirements for improved funding for these areas has been identified (Scaife et al., 2015). However, careful LCA is required to identify biofuels that are truly low-carbon. This is because advanced biofuels typically use feedstocks with more complex structure than first generation; therefore, more process steps are often required to transform the biomass into compatible fuels. As second generation processes generally remain at pilot and demonstration scale, these industries have not benefited from the decades of engineering improvements and scale-up/scale-down techniques for process optimization that have been realized by first generation biofuel production. There is opportunity to improve economics by providing funding and government support to process development engineering to improve productivity on an on-going basis. Further developments in transportation logistics and supply chains established by first generation biofuels could also enable ease of market access for the adoption of second generation fuel options.

Future prospects for feedstocks involve a movement into higher yields, residuals, and/or low transportation requirements. Although current commercial biofuels are produced primarily from field crops, forestry is the most abundant source which will be key to expanding production in the future. As identified by Mabee and Saddler (2010), utilization of forestry residuals and energy crops will also be critical movement for the biofuels industry to expand in Canada. Greater use of field crops will require policy drivers such as higher blending rates of biofuel in gasoline and diesel, as well as incentives for increased production in Canada. Agricultural residues are non-food feedstock for biofuel, however, will require improved technology and economics to achieve commercial production. Although livestock wastes represent the smallest agricultural feedstock in terms of available volume, they are the most effective feedstock for the reduction of GHG emissions.

Of course, economics plays a critical role in creating a self-sustaining biofuels industry. Biorefinery remains a key concept for improving the economics of the biofuels industry. Already in Canada, integrated pulp and paper biorefineries are paving the way, with manufacturers exploring the 
use of waste streams and by-products to produce biofuels and biochemicals. The reduced use of paper in Canada has caused this industry to become more creative. Potential waste streams include bark and wood waste, cooking liquor containing lignin and hemicelluloses, extractives including resins and triglycerides, and sludge from wastewater treatment (Girio et al., 2017). Examples include Alberta Pacific Forest Industries, Inc., which is producing industrial grade biomethanol (4000 tonnes/year) via stripping from waste gas streams for production of chlorine dioxide (Alberta Pacific Forest Industries Inc., 2017) and Domtar Corporation in partnership with FPInnovations (CelluForce), who are producing nanocrystalline cellulose from a kraft pulp stream at demonstration scale (CelluForce, 2017). The Sarnia biochemical cluster is another example of leveraging pre-existing infrastructure to build economical bioprocesses and this concept can be translated to biofuels production; however, for lower value biofuels low cost conversion technologies present a challenge, particularly for lignin. Again, funding and support for the development and innovation of new processes to improve conversion yields and productivity would be advantageous.

An opportunity for value-added products from some thermochemical processes is biochar, which is produced in significant amounts from pyrolysis and in limited amounts from gasification, as shown in Figure 7. Biochar has a wide range of applications including use as a soil amendment (Chan et al., 2007), solid fuel (Liu et al., 2013), electronic and battery applications (Gu et al., 2015), carbon emissions trading via carbon sequestration (Lehmann et al., 2006), and adsorption media (Mohan et al., 2014; Bhuiyan et al., 2017). When considering the sustainable lifecycle of biofuels in Canada and elsewhere, use as a soil amendment is particularly attractive, as nutrients stripped from the soil can be replaced.

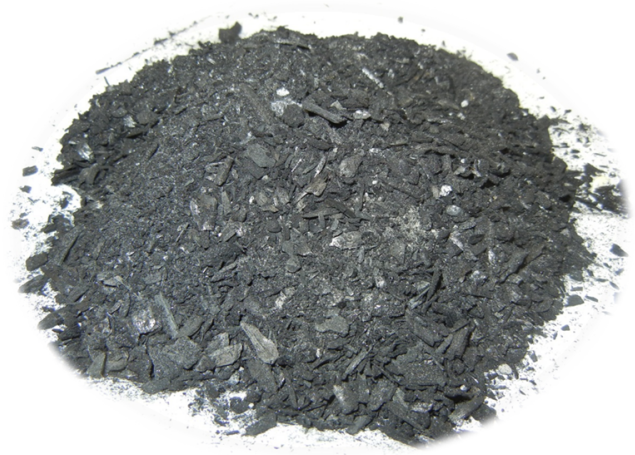

Fig. 7. Biochar produced from gasification (National Research Council Canada - Ottawa gasification unit).

In summary, the future prospects for liquid biofuel production in Canada are extensive and encouraging. With a concerted effort between academia, government, and industry, significant progress in this field is possible to help achieve Canada`s GHG emission reduction targets.

\section{References}

[1] Abdehagh, N., Dai, B., Thibault, J., Tezel, F.H., 2017. Biobutanol separation from ABE model solutions and fermentation broths using a combined adsorption-gas stripping process. J. Chem. Technol. Biotechnol. 92(1), 245-251.

[2] Abdehagh, N., Gurnani, P., Tezel, F.H., Thibault, J., 2015. Adsorptive separation and recovery of biobutanol from ABE model solutions. Adsorption. 21(3), 185-194.

[3] Abdehagh, N., Tezel, F.H., Thibault, J., 2014. Separation techniques in butanol production: challenges and developments. Biomass Bioenergy. $60,222-246$
[4] Abdehagh, N., Tezel, F.H., Thibault, J., 2016. Multicomponent adsorption modeling: isotherms for $\mathrm{ABE}$ model solutions using activated carbon F-400. Adsorption. 22(3), 357-370.

[5] Abdi, H.K., Alanazi, K.F., Rohani, A.S., Mehrani, P., Thibault, J., 2016. Economic comparison of a continuous ABE fermentation with and without the integration of an in situ vacuum separation unit. Can. J. Chem. Eng. 94(5), 833-843.

[6] ABRI-Tech, 2017. ABRI-Tech.

[7] Acharya, B., Roy, P., Dutta, A., 2014. Review of syngas fermentation processes for bioethanol. Biofuels. 5(5), 551-564

[8] Agarwal, A.K., 2007. Biofuels (alcohols and biodiesel) applications as fuels for internal combustion engines. Prog. Energy Combust. Sci. 33(3), 233-271.

[9] Agbor, V., Zurzolo, F., Blunt, W., Dartiailh, C., Cicek, N., Sparling, R., Levin, D.B., 2014. Single-step fermentation of agricultural hemp residues for hydrogen and ethanol production. Biomass Bioenergy. 64, 62-69.

[10] Aghbashlo, M., Demirbas, A., 2016. Biodiesel: hopes and dreads. Biofuel Res. J. 3(2), 379-379.

[11] Agriculture and Agri-Food Canada, 2015. Harper government supports new ethanol production technology.

[12] Agritherm, 2017. Agritherm.

[13] Ahmad, A.A., Zawawi, N.A., Kasim, F.H., Inayat, A., Khasri, A., 2016. Assessing the gasification performance of biomass: a review on biomass gasification process conditions, optimization and economic evaluation. Renew. Sust. Energy Rev. 53, 1333-1347.

[14] Akhtar, J., Amin, N.A.S., 2011. A review on process conditions for optimum bio-oil yield in hydrothermal liquefaction of biomass. Renew. Sust. Energy Rev. 15(3), 1615-1624.

[15] Alberta Pacific Forest Industries Inc, 2017. Alberta Pacific Forest Industries Inc

[16] Amara, A.B., Lecointe, B., Jeuland, N., Takahashi, T., Iida, Y., Hashimoto, H., Bouilly, J., 2014. Experimental study of the impact of diesel/biodiesel blends oxidation on the fuel injection systems. SAE Int. J. Fuels Lubr. 7(3), 849-860.

[17] Anis, S., Zainal, Z.A., 2011. Tar reduction in biomass producer gas via mechanical, catalytic and thermal methods: a review. Renew. Sust. Energy Rev. 15(5), 2355-2377.

[18] Anwar, A., Garforth, A., 2016. Challenges and opportunities of enhancing cold flow properties of biodiesel via heterogeneous catalysis. Fuel. 173, 189-208.

[19] Arnold, R.A., Habibi, R., Kopyscinski, J., Hill, J.M., 2017. Interaction of Potassium and Calcium in the Catalytic Gasification of Biosolids and Switchgrass. Energy Fuels. 31(6), 6240-6247.

[20] Asomaning, J., Mussone, P., Bressler, D.C., 2014. Two-stage thermal conversion of inedible lipid feedstocks to renewable chemicals and fuels. Bioresour. Technol. 158, 55-62.

[21] Assima, G.P., Dell'Orco, S., Navaee-Ardeh, S., Lavoie, J.M., 2017. Catalytic conversion of residual fine char recovered by aqueous scrubbing of syngas from urban biomass gasification. Biomass Bioenergy. 100, 98-107.

[22] Atabani, A.E., Silitonga, A.S., Badruddin, I.A., Mahlia, T.M.I., Masjuki, H.H., Mekhilef, S., 2012. A comprehensive review on biodiesel as an alternative energy resource and its characteristics. Renew. Sust. Energy Rev. 16(4), 2070-2093.

[23] Atlantic Biodiesel, 2017. Atlantic biodiesel.

[24] Barchyn, D., Cenkowski, S., 2014. Process analysis of superheated steam pre-treatment of wheat straw and its relative effect on ethanol selling price. Biofuel Res. J. 1(4), 123-128.

[25] Behnia, I., Yuan, Z., Charpentier, P., Xu, C.C., 2016. Production of methane and hydrogen via supercritical water gasification of renewable glucose at a relatively low temperature: effects of metal catalysts and supports. Fuel Process. Technol. 143, 27-34.

[26] Bhuiya, M.M.K., Rasul, M.G., Khan, M.M.K., Ashwath, N., Azad, A.K., Hazrat, M.A., 2014. Second generation biodiesel: potential alternative to-edible oil-derived biodiesel. Energy Procedia. 61, 1969-1972

[27] Bhuiyan, T.I., Tak, J.K., Sessarego, S., Harfield, D., Hill, J.M., 2017. Adsorption of acid-extractable organics from oil sands process- 
affected water onto biomass-based biochar: metal content matters. Chemosphere. 168, 1337-1344.

[28] BIOBUS Committee, 2003. Biodiesel demonstration and assesment with the Société de transport de Montréal (STM).

[29] Biodiesel Mandate for Diesel Fuel Regulation Reg. 147/2009, 2009. The Biofuels Act C.C.C.M. c.B40.

[30] Boboescu, I.Z., Gélinas, M., Beigbeder, J.B., Lavoie, J.M., 2017. A twostep optimization strategy for 2 nd generation ethanol production using softwood hemicellulosic hydrolysate as fermentation substrate. Bioresour. Technol. 244, 708-716.

[31] Boerringter, H., Calis, H.P., Slort, D.J., Bodenstaff, H., 2004. Gas Cleaning for Integrated biomass gasification (bg) and fischer-tropsch (ft) systems, experimental demonstration of two bg-ft systems, in: 2 nd world conference and technology exhibition on biomass for energy. Industry and Climate Protection. Rome, Italy.

[32] Boocock, D.G., Konar, S.K., Mao, V., Sidi, H., 1996. Fast one-phase oilrich processes for the preparation of vegetable oil methyl esters. Biomass Bioenergy. 11(1), 43-50.

[33] Bradburn, K., 2014. CanBio report on the status of bioenergy in Canada. Can. Bioenergy Assoc.

[34] Bradley, D., 2008. Canada report on bioenergy 2008.

[35] Breault, R.W., 2010. Gasification processes old and new: a basic review of the major technologies. Energies. 3(2), 216-240.

[36] Bridgwater, A.V., 2012. Review of fast pyrolysis of biomass and product upgrading. Biomass Bioenergy. 38, 68-94.

[37] Brown, A., 2017. IEA Technology Roadmap on Bioenergy, in: Bioenergy for the Future - Rollout of IEA Technology Roadmap on Bioenergy. Ottawa, Canada.

[38] Bruder, M., Moo-Young, M., Chung, D.A., Chou, C.P., 2015. Elimination of carbon catabolite repression in Clostridium acetobutylicum-a journey toward simultaneous use of xylose and glucose. Appl. Microbiol. Biotechnol. 99(18), 7579-7588.

[39] Canadian Biomass, 2014. IGPC Ethanol adopts Fiber Separation Technology.

[40] Cao, L., Tang, X., Zhang, X., Zhang, J., Tian, X., Wang, J., Xiong, M., Xiao, W., 2014. Two-stage transcriptional reprogramming in Saccharomyces cerevisiae for optimizing ethanol production from xylose. Metab. Eng. 24, 150-159.

[41] Carpenter, D., Westover, T.L., Czernik, S., Jablonski, W., 2014. Biomass feedstocks for renewable fuel production: a review of the impacts of feedstock and pretreatment on the yield and product distribution of fast pyrolysis bio-oils and vapors. Green Chem. 16(2), 384-406.

[42] CelluForce, 2017. Celluforce-technology.

[43] Chan, K.Y., Van Zwieten, L., Meszaros, I., Downie, A., Joseph, S., 2007. Agronomic values of greenwaste biochar as a soil amendment. Soil Res. 45(8), 629-634.

[44] Cheng, X., Ooms, M.D., Sinton, D., 2016. Biomass-to-biocrude on a chip via hydrothermal liquefaction of algae. Lab Chip. 16(2), 256-260.

[45] Chicago Board of Trade (CBOT), 2017.

[46] Chornet, E., Valsecchi, B., Avila, Y., Nguyen, B., Lavoie, J.M., 2011. Production of ethanol from methanol. U.S. Patent 8,080,693.

[47] Climate Change Central, 2009. Alberta renewable diesel demonstration.

[48] CNW Group, 2017. Shell signs agreement with SBI bioenergy Inc.

[49] Collotta, M., Champagne, P., Mabee, W., Tomasoni, G., Leite, G.B., Busi, L., Alberti, M., 2017. Comparative LCA of flocculation for the harvesting of microalgae for biofuels production. Procedia CIRP. 61, 756-760.

[50] Cowichan Biodiesel Coop, 2017. We eat locally, so do our cars.

[51] Dessureault, D., 2016. Canada Biofuels Annual, USDA Foreign Agricultural Service.

[52] Devi, L., Ptasinski, K.J., Janssen, F.J., 2003. A review of the primary measures for tar elimination in biomass gasification processes. Biomass Bioenergy. 24(2), 125-140.

[53] Dyer, J.A., Vergé, X.P.C., Desjardins, R.L., Worth, D.E., McConkey, B.G., 2010. The impact of increased biodiesel production on the greenhouse gas emissions from field crops in Canada. Energy Sust. Dev. 14(2), 73-82.

[54] Environment and Climate Change Canada (E.C.C.C.), 2017. Clean fuel standard: discussion paper.

[55] Enerkem, 2017. Enerkem.
[56] Ensyn, 2017. Ensyn.

[57] Ethanol General Regulation, 165/2007, 2007. The Biofuels Act C.C.S.M. c. B40.

[58] Ethanol in gasoline, 2017. Environmental Protection Act, R.S.O. 1990, c.E. 19, 2017. O.Reg. 535/05.

[59] Ethanol Producer Magazine.

[60] Farahani, M., Pagé, D.J.Y.S., Turingia, M.P., Tucker, B.D., 2009. Storage stability of biodiesel and ultralow sulfur diesel fuel blends. J. Energy Res. Technol. 131(4), 41801.

[61] Feng, S., Lin, Y.H., 2014. Ethanol fermentation under dissolved carbon dioxide control, in: Li, H., Y.J. (Eds.), Energy Procedia. 61, 2729-2732.

[62] Feng, S., Yuan, Z., Leitch, M., Xu, C.C., 2014. Hydrothermal liquefaction of barks into bio-crude-effects of species and ash content/composition. Fuel. 116, 214-220.

[63] Gao, K., Boiano, S., Marzocchella, A., Rehmann, L., 2014. Cellulosic butanol production from alkali-pretreated switchgrass (Panicum virgatum) and phragmites (Phragmites australis). Bioresour. Technol. 174, 176-181.

[64] Gao, K., Orr, V., Rehmann, L., 2016. Butanol fermentation from microalgae-derived carbohydrates after ionic liquid extraction. Bioresour. Technol. 206, 77-85.

[65] Gao, K., Rehmann, L., 2014. ABE fermentation from enzymatic hydrolysate of $\mathrm{NaOH}-$ pretreated corncobs. Biomass Bioenerg. 66 , $110-115$.

[66] Gao, K., Rehmann, L., 2016. Combined detoxification and in-situ product removal by a single resin during lignocellulosic butanol production. Sci. Rep. 6, 30533.

[67] Gardiner, D., 2017. Vapour space flammability measurements of high ethanol ("E85") and low ethanol ("E10") winter automotive fuels: effects of fuel composition and vapour pressure. SAE Int. J. Transp. Saf. 5(1), 68-80.

[68] Ge, S., Madill, M., Champagne, P., 2017. Use of freshwater macroalgae Spirogyra sp. for the treatment of municipal wastewaters and biomass production for biofuel applications. Biomass Bioenergy.

[69] George, E., Rentsen, B., Tabil, L.G., Meda, V., 2014. Optimization of wheat debranning using laboratory equipment for ethanol production. Int. J. Agric. Biol. Eng. 7(6), 54-66.

[70] Van Gerpen, J., 2005. Biodiesel processing and production. Fuel Process. Technol. 86(10), 1097-1107.

[71] Girio, F., Marques, S., Pinto, F., Oliveira, A.C., Cost, P., Reis, A., Moura, P., 2017. Biorefineries in the world, in: Rabaçal, M., Ferreira, A.F., Silva, C.A.M., Costa, M. (Eds.), Biorefineries: Targeting Energy, High Value Products and Waste Valorization. Springer, pp. 227-281.

[72] Global Forest Watch - Country Profiles, 2017.

[73] Görgens, J.F., Bressler, D.C., Van Rensburg, E., 2015. Engineering Saccharomyces cerevisiae for direct conversion of raw, uncooked or granular starch to ethanol. Crit. Rev. Biotechnol. 35(3), 369-391.

[74] Graham, L.A., Belisle, S.L., Baas, C.L., 2008. Emissions from light duty gasoline vehicles operating on low blend ethanol gasoline and E85. Atmos. Environ. 42(19), 4498-4516.

[75] Green Power Inc., 2014. Landfill Tipping Fees in the U.S.

[76] Greener diesel - renewable fuel content requirements for petroleum diesel fuel, 2014. Environmental Protection Act, R.S.O.1990, c.E.19, O. Reg. 97/14

[77] GreenField Global, 2017. GreenField Global evaluating major expansion of biofuels production in Varennes, Quebec.

[78] Gu, X., Wang, Y., Lai, C., Qiu, J., Li, S., Hou, Y., Martens, W., Mahmood, N., Zhang, S., 2015. Microporous bamboo biochar for lithium-sulfur batteries. Nano Res. 8(1), 129-139.

[79] Gumba, R.E., Saallah, S., Misson, M., Ongkudon, C.M., Anton, A., 2016. Green biodiesel production: a review on feedstock, catalyst, monolithic reactor, and supercritical fluid technology. Biofuel Res. J. 3(3), 431-447.

[80] Haefele, D.M., Combs, E.E., 2017. Corn: genetics, composition and quality, in: Walker,G. M., Abbas, C., Ingledew, W.M., Pilgrim, C. (Eds.), The alcohol textbook, 6th edition: a reference for the fuel alcohol and distilled spirits industries, pp. 41-54. 
[81] Harner, N.K., Bajwa, P.K., Habash, M.B., Trevors, J.T., Austin, G.D., Lee, H., 2014. Mutants of the pentose-fermenting yeast Pachysolen tannophilus tolerant to hardwood spent sulfite liquor and acetic acid. Antonie van Leeuwenhoek. 105(1), 29-43.

[82] Harner, N.K., Wen, X., Bajwa, P.K., Austin, G.D., Ho, C.Y., Habash, M.B., Trevors, J.T., Lee, H., 2015. Genetic improvement of native xylose-fermenting yeasts for ethanol production. J. Ind. Microbiol. Biotechnol. 42(1), 1-20.

[83] Hoekman, S.K., Gertler, A., Broch, A., Robbins, C., 2009. Investigation of biodistillates as potential blendstocks for transportation fuels. Report no. CRC AVFL-17.

[84] Hoekman, S.K., Robbins, C., 2012. Review of the effects of biodiesel on NOx emissions. Fuel Process. Technol. 96, 237-249.

[85] Hogan, E., 1994. Overview of Canadian thermochemical biomass conversion activities, in: Bridgewater, A.V. (Ed.), Advances in Thermochemical Biomass Conversion. Springer, pp. 15-25.

[86] Hollebone, B.P., Fieldhouse, B., Landriault, M., Doe, K., Jackman, P., 2008. Aqueous solubility, dispersibility and toxicity of biodiesels. Int. Oil Spill Conf. Proc. 2008(1), 929-936.

[87] Hu, J., Yu, F., Lu, Y., 2012. Application of fischer-tropsch synthesis in biomass to liquid conversion. Catalysts. 2(2), 303-326.

[88] Huber, G.W., O'Connor, P., Corma, A., 2007. Processing biomass in conventional oil refineries: production of high quality diesel by hydrotreating vegetable oils in heavy vacuum oil mixtures. Appl. Catal., A. $329,120-129$.

[89] Imperial Oil, 2009. Biodiesel research project final report summary. Report R658-2009.

[90] International Energy Agency, 2017. Technology roadmap-delivering sustainable bioenergy.

[91] Jin, Y., Parashar, A., Mason, B., Bressler, D.C., 2016. Simultaneous hydrolysis and co-fermentation of whey lactose with wheat for ethanol production. Bioresour. Technol. 221, 616-624.

[92] Jindal, M.K., Jha, M.K., 2015. Effect of process conditions on hydrothermal liquefaction of biomass. I.J.C.B.S. Res. Pap. 2(8),

[93] Johnson, E., Sarchami, T., Kießlich, S., Munch, G., Rehmann, L., 2016. Consolidating biofuel platforms through the fermentative bioconversion of crude glycerol to butanol. World J. Microbiol. Biotechnol. 32(6), 103.

[94] Johnson, E.E., Rehmann, L., 2016. The role of 1,3-propanediol production in fermentation of glycerol by Clostridium pasteurianum. Bioresour. Technol. 209, 1-7.

[95] Joyce, B.L., Zheljazkov, V.D., Sykes, R., Cantrell, C.L., Hamilton, C., Mann, D.G.J., Rodriguez, M., Mielenz, J.R., Astatkie, T., Stewart Jr., C.N., 2015. Ethanol and high-value terpene co-production from lignocellulosic biomass of Cymbopogon flexuosus and Cymbopogon martinii. PLoS One. 10(10), e0139195.

[96] Kang, K., Azargohar, R., Dalai, A.K., Wang, H., 2016. Hydrogen production from lignin, cellulose and waste biomass via supercritical water gasification: catalyst activity and process optimization study. Energy Convers. Manage. 117, 528-537.

[97] Khosravanipour Mostafazadeh, A., Drogui, P., Brar, S.K., Tyagi, R.D., Le Bihan, Y., Buelna, G., Rasolomanana, S.D., 2016. Enhancement of biobutanol production by electromicrobial glucose conversion in a dual chamber fermentation cell using C. pasteurianum. Energy Convers. Manage. 130, 165-175.

[98] Kießlich, S., Sarchami, T., Munch, G., Gao, K., Rehmann, L., Kujawski, W., Johnson, E., 2017. Pervaporative butanol removal from PBE fermentation broths for the bioconversion of glycerol by Clostridium pasteurianum. J. Membr. Sci. 535, 79-88.

[99] Knothe, G., Steidley, K.R., 2005. Lubricity of components of biodiesel and petrodiesel. the origin of biodiesel lubricity. Energy Fuels. 19(3), 1192-1200

[100] Koh, M.Y., Mohd. Ghazi, T.I.M., 2011. A review of biodiesel production from Jatropha curcas L. oil. Renew. Sust. Energy Rev. 15(5), 2240-2251.

[101] Kohl, S., 2017. Grain mashing for fuel alcohol, in: Walker, G.M., Abbas, C., Ingledew, W.M., Pilgrim, C. (Eds.), The Alcohol Textbook. pp. 181192.

[102] Kohl, S., Singh, V., 2017. New technologies in dry grind ethanol process, in: Walker, G.M., Abbas, C., Ingledew, W.M., Pilgrim, C. (Eds.), The Alcohol Textbook. pp. 557-571.
[103] Kutney, G., 2017. Celebrating Canada's 150th: a short history of the biofuel industry in Canada. Biofuels Dig.

[104] Laan, T., Litman, T., Steenblik, R., 2009. Biofuels-at what cost? government support for ethanol and biodiesel in Canada. Global Subsidies Iniative (GSI), International Institute for Sustainable Development (IISD).

[105] Lambert, N., 2012a. Study of hydrogenation derived renewable diesel as a renewable fuel option in North America. Natural Resources Canada. Montreal.

[106] Lambert, N., 2012b. An update on renewable diesel infrastructure in canada-final report. Natural Resources Canada. Montreal.

[107] Lanahan, M.B., Basu, S.S., Batie, C.J., Chen, W., Craig, J., Kinkema, M., 2006. Self-process. plants and plant parts. U.S. Patent 7,102,057B2.

[108] Lapuerta, M., Villajos, M., Agudelo, J.R., Boehman, A.L., 2011. Key properties and blending strategies of hydrotreated vegetable oil as biofuel for diesel engines. Fuel Process. Technol. 92(12), 2406-2411.

[109] Larson, E.D., 2006. A review of life-cycle analysis studies on liquid biofuel systems for the transport sector. Energy Sust. Dev. 10(4), 109126.

[110] Lavoie, J.M., Marie-Rose, S., Lynch, D., 2013. Non-homogeneous residual feedstocks to biofuels and chemicals via the methanol route. Biomass Convers. Biorefin. 3(1), 39-44.

[111] Le Roy, D., Klein, K.K., 2012. The policy objectives of a biofuel industry in Canada: an assessment. Agriculture. 2(4), 436-451.

[112] Lehmann, J., Gaunt, J., Rondon, M., 2006. Bio-char sequestration in terrestrial ecosystems-a review. Mitigation and Adaptation Strategies for Global Change. 11(2), 403-427.

[113] Levasseur, A., Bahn, O., Beloin-Saint-Pierre, D., Marinova, M. Vaillancourt, K., 2017a. Assessing butanol from integrated forest biorefinery: a combined techno-economic and life cycle approach. Appl. Energy. 198, 440-452.

[114] Levasseur, A., Bahn, O., Beloin-Saint-Pierre, D., Marinova, M., Vaillancourt, K., 2017b. Assessing butanol from integrated forest biorefinery: a combined techno-economic and life cycle approach. Appl. Energy. 198, 440-452

[115] Li, J., Vasanthan, T., Gao, J., Naguleswaran, S., Zijlstra, R.T., Bressler, D.C., 2014. Resistant starch escaped from ethanol production: evidence from confocal laser scanning microscopy of distiller's dried grains with solubles (DDGS). Cereal Chem. 91(2), 130-138.

[116] Li, X., Luque-Moreno, L.C., Oudenhoven, S.R., Rehmann, L. Kersten, S.R., Schuur, B., 2016. Aromatics extraction from pyrolytic sugars using ionic liquid to enhance sugar fermentability. Bioresour. Technol. 216, 12-18.

[117]Lin, Y.H., Liu, C.G., 2014. Process design for very-high-gravity ethanol fermentation, in: Li, H., Y.J. (Ed.), Energy Procedia. Elsevier Ltd. 61, 2725-2728.

[118] Liu, C.G., Liu, L.Y., Lin, Y.H., Bai, F.W., 2015. Kinetic modeling for redox potential-controlled repeated batch ethanol fermentation using flocculating yeast. Process Biochem. 50(1), 1-7.

[119] Liu, K., 2011. Chemical composition of distillers grains, a review. J. Agric. Food Chem. 59(5), 1508-1526.

[120] Liu, Z., Quek, A., Hoekman, S.K., Balasubramanian, R., 2013. Production of solid biochar fuel from waste biomass by hydrothermal carbonization. Fuel. 103, 943-949.

[121] Luque, L., Oudenhoven, S., Westerhof, R., van Rossum, G., Berruti, F., Kersten, S., Rehmann, L., 2016. Comparison of ethanol production from corn cobs and switchgrass following a pyrolysisbased biorefinery approach. Biotechnol. Biofuels. 9(1), 242.

[122] Luque, L., Westerhof, R., Van Rossum, G., Oudenhoven, S., Kersten, S., Berruti, F., Rehmann, L., 2014. Pyrolysis based bio-refinery for the production of bioethanol from demineralized ligno-cellulosic biomass. Bioresour. Technol. 161, 20-28.

[123] Ma, F., Hanna, M.A., 1999. Biodiesel production: a review. Bioresour. Technol. 70(1), 1-15.

[124] Mabee, W.E., Saddler, J.N., 2010. Bioethanol from lignocellulosics: status and perspectives in Canada. Bioresour. Technol. 101(13), 4806-4813. 
[125] Maiti, S., Gallastegui, G., Kaur Brar, S., Lebihan, Y., Buelna, G., Drogui, P., Verma, M., 2016. Quest for sustainable bio-production and recovery of butanol as a promising solution to fossil fuel. Int. J. Energy Res. 40(4), 411-438.

[126] Maiti, S., Gallastegui, G., Sarma, S.J., Brar, S.K., Le Bihan, Y., Drogui, P., Buelna, G., Verma, M., 2016b. A re-look at the biochemical strategies to enhance butanol production. Biomass Bioenergy. 94, 187-200.

[127] Maiti, S., Sarma, S.J., Brar, S.K., Le Bihan, Y., Drogui, P., Buelna, G., Verma, M., 2016d. Agro-industrial wastes as feedstock for sustainable bio-production of butanol by Clostridium beijerinckii. Food Bioprod. Process. 98, 217-226.

[128] Mara Renewables Corporation, 2017. Mara renewables corporation.

[129] Math, M.C., Kumar, S.P., Chetty, S.V., 2010. Technologies for biodiesel production from used cooking oil-a review. Energy Sust. Dev. 14(4), 339-345.

[130] McCarthy, S., 2013. Ottawa ending biofuels subsidy over unfulfilled industry promises. The Globe and Mail.

[131] Mechmech, F., Chadjaa, H., Rahni, M., Marinova, M., Akacha, N.B., Gargouri, M., 2015. Improvement of butanol production from a hardwood hemicelluloses hydrolysate by combined sugar concentration and phenols removal. Bioresour. Technol. 192, 287-295

[132] Mechmech, F., Marinova, M., Chadjaa, H., Rahni, M., Akacha, N.B., Gargouri, M., 2015. Alfalfa juice as a nitrogen source or supplement for acetone-butanol-ethanol production by Clostridium acetobutylicum. Ind. Crops Prod. 78, 73-81.

[133] Mechmech, F., Marinova, M., Chadjaa, H., Rahni, M., Akacha, N.B., Gargouri, M., 2016. Co-fermentation of alfalfa juice and hardwood hydrolysate for butanol production in combined biorefinery systems. Ind. Crops Prod. 89, 29-33.

[134] Meier, D., van de Beld, B., Bridgwater, A.V., Elliott, D.C., Oasmaa, A., Preto, F., 2013. State-of-the-art of fast pyrolysis in IEA bioenergy member countries. Renew. Sust. Energy Rev. 20, 619-641.

[135] Miller, P., Kumar, A., 2014. Techno-economic assessment of hydrogenation-derived renewable diesel production from canola and camelina. Sust. Energy Technol. Assess. 6, 105-115.

[136] Mirhosseini, S., Barchyn, D., Agbor, V.B., Levin, D.B., Cenkowski, S., 2016. The effect of superheated steam pretreatment of wheat straw on fermentation. Can. Biosyst. Eng. 58, 8.9-8.17.

[137] M.J. Ervin and Associates, 2007. Canada's downstream logical infrastructure: refining, pipelines, terminals, bulk plants and cardlocks.

[138] Mohan, D., Pittman, C.U., Steele, P.H., 2006. Pyrolysis of wood/biomass for bio-oil: a critical review. Energy Fuels. 20(3), 848-889.

[139] Mohan, D., Sarswat, A., Ok, Y.S., Pittman, C.U., 2014. Organic and inorganic contaminants removal from water with biochar, a renewable, low cost and sustainable adsorbent -a critical review. Bioresour. Technol. $160,191-202$

[140] Monceaux, D.A., 2017. Dryhouse technology, in: Walker, G.M., Abbas, W.M., Ingledew, W.M., Pilgrim, C. (Eds.), The Alcohol Textbook, pp. 155-179.

[141] Moorhouse, J., Wolinetz, M., 2016. Biofuels in Canada: tracking progress in tackling greenhouse gas emissions from transportation fuels. Clean Energy Canada.

[142] Mortensen, P.M., Grunwaldt, J.D., Jensen, P.A., Knudsen, K.G., Jensen, A.D., 2011. A review of catalytic upgrading of bio-oil to engine fuels. Appl. Catal., A. 407(1-2), 1-19.

[143] Munshaw, S., Hertz, P.B., 2006. Saskatoon biobus-phase II final research report.

[144] Mupondwa, E., Li, X., Tabil, L., Sokhansanj, S., Adapa, P., 2017. Status of Canada's lignocellulosic ethanol: part II: hydrolysis and fermentation technologies. Renew. Sust. Energy Rev. 79, 1535-1555

[145] Mustafa, I.H., Fgaier, H., Elkamel, A., Lohi, A., Ibrahim, G., Elnashaie, S.S.E.H., 2014. Effect of the feed substrate concentration on the dynamic performance of the bioethanol fermentation process using Zymomonas mobiliz. Energy Fuels. 28(8), 5543-5556.

[146] N'Diaye, A., Hucl, P.J., Haile, J.K., Pozniak, C.J., 2017. Wheat: genetics, composition and quality, in: Walker, M., Abbas, C., Ingledew, W.M., Pilgrim, C. (Eds.), The Alcohol Textbook. pp. 55-73.

[147] Naik, S.N., Goud, V.V., Rout, P.K., Dalai, A.K., 2010. Production of first and second generation biofuels: a comprehensive review. Renew. Sust. Energy Rev. 14(2), 578-597.
[148] Nanda, S., Mohammad, J., Reddy, S.N., Kozinski, J.A., Dalai, A.K. 2014a. Pathways of lignocellulosic biomass conversion to renewable fuels. Biomass Convers. Biorefin. 4(2), 157-191.

[149] Nanda, S., Dalai, A.K., Kozinski, J.A., 2014b. Butanol and ethanol production from lignocellulosic feedstock: biomass pretreatment and bioconversion. Energy Sci. Eng. 2(3), 138-148.

[150] Nanda, S., Isen, J., Dalai, A.K., Kozinski, J.A., 2016. Gasification of fruit wastes and agro-food residues in supercritical water. Energy Convers. Manage. 110, 296-306.

[151] Nanda, S., Golemi-Kotra, D., McDermott, J.C., Dalai, A.K., Gökalp I., Kozinski, J.A., 2017. Fermentative production of butanol: perspectives on synthetic biology. New Biotechnol. 37, 210-221.

[152] National Forestry Database - Forest Inventory, 2017

[153] Nazari, L., Yuan, Z., Souzanchi, S., Ray, M.B., Xu, C.C., 2015 Hydrothermal liquefaction of woody biomass in hot-compressed water: catalyst screening and comprehensive characterization of biocrude oils. Fuel. 162, 74-83.

[154] Nigam, P.S., Singh, A., 2011. Production of liquid biofuels from renewable resources. Prog. Energy Combust. Sci. 37(1), 52-68.

[155] No, S.Y., 2014. Application of hydrotreated vegetable oil from triglyceride based biomass to CI engines-a review. Fuel. 115, 88-96.

[156] NRCan, 2010. Report on the technical feasibility of integrating an annual average $2 \%$ renewable diesel in the canadian distillate pool by 2011

[157] NRCan, 2016. The ecoEnergy for biofuels program-about the incentive.

[158] NRCan, 2017. Bioenergy systems

[159] Ofuonye, E., Kutin, K., Stuart, D.T., 2013. Engineering Saccharomyces cerevisiae fermentative pathways for the production of isobutanol. Biofuels. 4(2), 185-201.

[160] Oo, A.N., Hewson, W.D., Albion, K.J., 2010. Assessment of Agricultural Residues as a Biomass Fuel for Ontario Power Generation.The Research Park, London.

[161] Parashar, A., Jin, Y., Mason, B., Chae, M., Bressler, D.C., 2016 Incorporation of whey permeate, a dairy effluent, in ethanol fermentation to provide a zero waste solution for the dairy industry. J. Dairy Sci. 99(3), 1859-1867.

[162] Paré, D., Bernier, P., Thiffault, E., Titus, B., 2017. The potential of forest biomass as an energy supply for Canada. For. Chron. 87(1), 7176.

[163] Patel, M., Kumar, A., 2016. Production of renewable diesel through the hydroprocessing of lignocellulosic biomass-derived bio-oil: a review. Renew. Sust. Energy Rev. 58, 1293-1307.

[164] Patzlaff, J., Liu, Y., Graffmann, C., Gaube, J., 1999. Studies on product distributions of iron and cobalt catalyzed Fischer-Tropsch synthesis. Appl. Catal., A. 186(1-2), 109-119.

[165] Peris, D., Moriarty, R.V., Alexander, W.G., Baker, E., Sylvester, K. Sardi, M., Langdon, Q.K., Libkind, D., Wang, Q.M., Bai, F.Y., Leducq, J.B., Charron, G., Landry, C.R., Sampaio, J.P., Gonçalves, P., Hyma, K.E., Fay, J.C., Sato, T.K., Hittinger, C.T., 2017. Hybridization and adaptive evolution of diverse Saccharomyces species for cellulosic biofuel production. Biotechnol. Biofuels. 10(1), 78.

[166] Peterson, A.A., Vogel, F., Lachance, R.P., Fröling, M., Antal Jr, M.J., Tester, J.W., 2008. Thermochemical biofuel production in hydrothermal media: a review of sub- and supercritical water technologies. Energy Environ. Sci. 1(1), 32-65.

[167] Pond Technologies, 2017. Pond technologies.

[168] Porth, I., El-Kassaby, Y.A., 2015a. Using Populus as a lignocellulosic feedstock for bioethanol. Biotechnol. J. 10(4), 510-524.

[169] Pyne, M.E., Moo-Young, M., Chung, D.A., Chou, C.P., 2014 Expansion of the genetic toolkit for metabolic engineering of Clostridium pasteurianum: chromosomal gene disruption of the endogenous CpaAI restriction enzyme. Biotechnol. Biofuels. 7(1), 163.

[170] Pyne, M.E., Sokolenko, S., Liu, X., Srirangan, K., Bruder, M.R., Aucoin, M.G., Moo-Young, M., Chung, D.A., Chou, C.P., 2016. Disruption of the reductive 1,3-propanediol pathway triggers production of 1,2-propanediol for sustained glycerol fermentation by 
Clostridium pasteurianum. Appl. Environ. Microbiol. 82(17), 5375-5388.

[171] Pyrobiom, 2017. Pyrobiom energies.

[172] Renewable and Low Carbon Fuel Requirements Regulations, B.C. Reg. 394/2008, 2017. Greenhouse Gas Reduction (Renewable and Low Carbon Fuel Requirements ) Act.

[173] Renewable Fuels Regulations, 2013. SOR/2010-189.

[174] Renewable Fuels Standard Regulation, A.R. 29/2010, 2012. Climate change and emissions management act.

[175] Regestein, L., Doerr, E.W., Staaden, A., Rehmann, L., 2015. Impact of butyric acid on butanol formation by Clostridium pasteurianum. Bioresour. Technol. 196, 153-159.

[176] RIC, 2017. Renewable industries canada - industry map.

[177] Rilett, J., Gagnon, A., 2008. Renewable diesel characterization study. Climate Change Central.

[178] Rosentrater, K.A., 2017. Beverage and fuel alcohol distillers' coproducts - production, economics, and use as animal feed, in: Walker, G.M., Abbas, C., Ingledew, W.M., Pilgrim, C. (Eds.), The Alcohol Textbook. pp. 489-510.

[179] Roy, P., Dutta, A., Deen, B., 2015. Greenhouse gas emissions and production cost of ethanol produced from biosyngas fermentation process. Bioresour. Technol. 192, 185-191.

[180] Sai Prasad, P.S., Bae, J.W., Kang, S.H., Lee, Y.J., Jun, K.W., 2008. Single-step synthesis of DME from syngas on $\mathrm{Cu}-\mathrm{ZnO}-\mathrm{Al} 2 \mathrm{O}$ /zeolite bifunctional catalysts: the superiority of ferrierite over the other zeolites. Fuel Process. Technol. 89(12), 1281-1286.

[181] Sapp, M., 2017. IGPC celebrates company's expansion doubling ethanol production by 2018. Biofuels Digest.

[182] Sarchami, T., Rehmann, L., 2014. Optimizing enzymatic hydrolysis of inulin from Jerusalem artichoke tubers for fermentative butanol production. Biomass Bioenergy. 69, 175-182.

[183] Sarchami, T., Rehmann, L., 2015. Optimizing acid hydrolysis of jerusalem artichoke-derived inulin for fermentative butanol production. Bioenergy Res. 8(3), 1148-1157.

[184] Sarchami, T., Johnson, E., Rehmann, L., 2016a. Optimization of fermentation condition favoring butanol production from glycerol by Clostridium pasteurianum DSM 525. Bioresour. Technol. 208, 73-80.

[185] Sarchami, T., Munch, G., Johnson, E., Kießlich S., Rehmann, L., $2016 b$. A review of process-design challenges for industrial fermentation of butanol from crude glycerol by non-biphasic Clostridium pasteurianum. Ferment. 2, 1-33.

[186] Savage, P.E., Levine, R.B., Huelsman, C.M., 2010a. Thermochemical Conversion of Biomass to Liquid Fuels and Chemicals, RSC Energy and Environment Series. Royal Society of Chemistry, Cambridge.

[187] SBI Bioenergy, 2017. SBI BioEnergy Inc.

[188] Scaife, M.A., Merkx-Jacques, A., Woodhall, D.L., Armenta, R.E., 2015. Algal biofuels in Canada: status and potential. Renew. Sust. Energy Rev. 44, 620-642.

[189] SDTC, 2017. Sustainable development technology canada-projects.

[190] Serate, J., Xie, D., Pohlmann, E., Donald, C., Shabani, M., Hinchman, L., Higbee, A., McGee, M., Reau, A., Klinger, G.E., Li, S., Myers, C.L., Boone, C., Bates, D.M., Cavalier, D., Eilert, D., Oates, L.G., Sanford, G., Sato, T.K., Dale, B., Landick, R., Piotrowski, J., Ong, R.G., Zhang, Y., 2015. Controlling microbial contamination during hydrolysis of AFEXpretreated corn stover and switchgrass: effects on hydrolysate composition, microbial response and fermentation. Biotechnol. Biofuels 8(1), 180.

[191] Shadbahr, J., Khan, F., Zhang, Y., 2017. Kinetic modeling and dynamic analysis of simultaneous saccharification and fermentation of cellulose to bioethanol. Energy Convers. Manage. 141, 236-243.

[192] Shadbahr, J., Zhang, Y., Khan, F., 2014. Life Cycle Assessment of bioethanol production from woodchips with modifications in the pretreatment process. Appl. Biochem. Biotechnol. 175(2), 1080-1091.

[193] Sharif Rohani, A., Mehrani, P., Thibault, J., 2015. Comparison of in-situ recovery methods of gas stripping, pervaporation, and vacuum separation by multi-objective optimization for producing biobutanol via fermentation process. Can. J. Chem. Eng. 93(6), 986-997.

[194] Shen, Y., Yoshikawa, K., 2013. Recent progresses in catalytic tar elimination during biomass gasification or pyrolysis-a review. Renew. Sust. Energy Rev. 21, 371-392.
[195] Silva, J.B., Sauvageau, D., 2014. Bacteriophages as antimicrobial agents against bacterial contaminants in yeast fermentation processes. Biotechnol. Biofuels. 7(1), 123.

[196] Sims, R., Taylor, M., Saddler, J., Mabee, W., 2008. From 1st to 2nd generation biofuel technologies, an overview of current industry and RD\&D activities. IEA, Paris, France.

[197] Singh, S.P., Singh, D., 2010. Biodiesel production through the use of different sources and characterization of oils and their esters as the substitute of diesel: a review. Renew. Sust. Energy Rev. 14(1), 200216.

[198] Singh, V., Kohl, S., 2017. Co-products from fuel alcohol plants, in: Walker, G.M., Abbas, C., Ingledew, W.M., Pilgrim, C. (Eds.), The Alcohol Textbook. pp. 511-527.

[199] Souligny, M., Graham, L., Rideout, G., Hosatte, P., 2004. Heavy-duty diesel engine performance and emission measurements for different biodiesel blends used in the Montreal BIOBUS project. SAE Technical paper 2004-01-1861.

[200] Steeper Energy, 2017. Steeper energy.

[201] Stumborg, M., Wong, A., Hogan, E., 1996. Hydroprocessed vegetable oils for diesel fuel improvement. Bioresour. Technol. 56(1), 13-18

[202] Suckling, I.D., Jack, M.W., Lloyd, J.A., Murton, K.D., Newman, R.H., Stuthridge, T.R., Torr, K.M., Vaidya, A.A., 2017. A mild thermomechanical process for the enzymatic conversion of radiata pine into fermentable sugars and lignin. Biotechnol. Biofuels. 10(1), 61.

[203] Surisetty, V.R., Kozinski, J., Dalai, A.K., 2012. Biomass, availability in Canada, and gasification: an overview. Biomass Convers. Biorefin. 2(1), 73-85.

[204] Tabatabaei, M., Karimi, K., Sárvári Horváth, I., Kumar, R., 2015. Recent trends in biodiesel production. Biofuel Res. J. 2(3), 258-267.

[205] The Ethanol Fuel (General) Regulations, Reg. 1/2015, 2015. The Ethanol Fuels Act, E-11.1.

[206] The Renewable Diesel Regulations, Reg. 1/2012, 2012. Renewable Diesel Act, R-19.001.

[207] Tian, X., Rehmann, L., Xu, C.C., Fang, Z., 2016. Pretreatment of eastern white pine (Pinus strobes L.) for enzymatic hydrolysis and ethanol production by organic electrolyte solutions. ACS Sust. Chem. Eng. 4(5), 2822-2829.

[208] Toor, S.S., Rosendahl, L., Rudolf, A., 2011. Hydrothermal liquefaction of biomass: a review of subcritical water technologies. Energy. 36(5), 2328-2342.

[209] U.S. Grains Council, 2012. A guide to distiller's dried grains with solubles. 3rd Edition. pp. 406.

[210] U.S. Environmental Protection Agency (E.P.A.), 2010. Renewable fuel standard program (RFS2) regulatory impact analysis (EPA-420R-10-006).

[211] Verma, M., Godbout, S., Brar, S. K., Solomatnikova, O., Lemay, S.P. Larouche, J.P., 2012. Biofuels production from biomass by thermochemical conversion technologies. Int. J. Chem. Eng. 2012.

[212] Volynets, B., Ein-Mozaffari, F., Dahman, Y., 2017. Biomass processing into ethanol: pretreatment, enzymatic hydrolysis, fermentation, rheology, and mixing. Green Process. Synth. 6(1).

[213] Wang, J., Chae, M., Sauvageau, D., Bressler, D.C., 2017. Improving ethanol productivity through self-cycling fermentation of yeast: a proof of concept. Biotechnol. Biofuels. 10(1), 193.

[214] Wang, Z., Dunn, J.B., Han, J., Wang, M.Q., 2015. Influence of corn oil recovery on life-cycle greenhouse gas emissions of corn ethanol and corn oil biodiesel. Biotechnol. Biofuels. 8, 178 .

[215] Westman, J.O., Wang, R., Novy, V., Franzén, C.J., 2017. Sustaining fermentation in high-gravity ethanol production by feeding yeast to a temperature-profiled multifeed simultaneous saccharification and cofermentation of wheat straw. Biotechnol. Biofuels. 10, 213.

[216] Whalen, J., Xu, C., Shen, F., Kumar, A., Eklund, M., Yan, J., 2017. Sustainable biofuel production from forestry, agricultural and waste biomass feedstocks. Appl. Energy. 198, 281-283.

[217] Wolinetz, M., Hein, M., 2017. Biofuels in Canada 2017-Tracking biofuel consumption, feedstocks and avoided greenhouse gas emissions. Navius Research, Vancouver, BC. 
[218] Wong, A., Zhang, H., Kumar, A., 2016. Life cycle assessment of renewable diesel production from lignocellulosic biomass. Int. J. Life Cycle Assess. 21(10), 1404-1424.

[219] Wood, J.A., Orr, V.C.A., Luque, L., Nagendra, V., Berruti, F., Rehmann, L., 2015. High-throughput screening of inhibitory compounds on growth and ethanol production of saccharomyces cerevisiae. Bioenergy Res. 8(1), 423-430.

[220] Wood, S.M., Layzell, D.B., 2003. A Canadian biomass inventory: feedstocks for a bio-based economy. Biocap Canada Foundation, Kingston.

[221] Woodland Biofuels Inc., 2017. Woodland biofuels Inc.

[222] Xiong, L., Maki, M., Guo, Z., Mao, C., Qin, W., 2014. Agave biomass is excellent for production of bioethanol and xylitol using Bacillus Strain 65S3 and Pseudomonas strain CDS3. J. Biobased Mater. Bioenergy. 8(4), 422-428.

[223] Yang, J., Song, J., Liang, S., Guan, R., Shi, Y., Yu, W., Zhu, S., Fan, W., Hou, H., Hu, J., Deng, H., Xiao, B., 2017. Synergistic effect of water content and composite conditioner of Fenton's reagent combined with red mud on the enhanced hydrogen production from sludge pyrolysis. Water Res. 123, 378-387.
[224] Yu, Y., Christopher, L.P., 2017. Detoxification of hemicellulose-rich poplar hydrolysate by polymeric resins for improved ethanol fermentability. Fuel. 203, 187-196.

[225] Yuan, Z., Wen, Y., 2017. Evaluation of an integrated process to fully utilize bamboo biomass during the production of bioethanol. Bioresour. Technol. 236, 202-211

[226] Yuan, Z., Wen, Y., Kapu, N.S., Beatson, R., Mark Martinez, D., 2017. A biorefinery scheme to fractionate bamboo into high-grade dissolving pulp and ethanol. Biotechnol. Biofuels. 10, 38.

[227]Zhang, Q., Chang, J., Wang, T., Xu, Y., 2007. Review of biomass pyrolysis oil properties and upgrading research. Energy Convers. Manage. 48(1), 87-92.

[228] Zhao, R., Wu, X., Seabourn, B.W., Bean, S.R., Guan, L., Shi, Y.C., Wilson, J.D., Madl, R., Wang, D., 2009. Comparison of waxy vs. nonwaxy wheats in fuel ethanol fermentation. Cereal Chem. J. 86(2), $145-156$

[229] Zhen, X., Wang, Y., 2015. An overview of methanol as an internal combustion engine fuel. Renew. Sust. Energy Rev. 52, 477-493. 